\title{
Nanotechnologies in Food Science: Applications, Recent Trends, and Future Perspectives
}

Cite as

Nano-Micro Lett.

(2020) 12:45

Received: 5 November 2019

Accepted: 31 December 2019

Published online: 4 February 2020

(C) The Author(s) 2020

\author{
Shivraj Hariram Nile ${ }^{1}$, Venkidasamy Baskar ${ }^{2}$, Dhivya Selvaraj $^{2}$, Arti Nile $^{3}$, \\ Jianbo Xiao ${ }^{4}$, Guoyin $\mathrm{Kai}^{1}{ }^{凶}$ \\ Shivraj Hariram Nile and Venkidasamy Baskar contributed equally to this work. \\ $\triangle$ Shivraj Hariram Nile, nileshivraj@yahoo.com; Guoyin Kai, kaiguoyin@163.com \\ 1 Laboratory of Medicinal Plant Biotechnology, College of Pharmacy, Zhejiang Chinese Medical University, \\ Hangzhou 310053, Zhejiang, People's Republic of China \\ 2 Plant Genetic Engineering Laboratory, Department of Biotechnology, Bharathiar University, Coimbatore, \\ Tamil Nadu, India \\ 3 Department of Bioresources and Food Science, Sanghuh College of Life Sciences, Konkuk University, \\ Seoul 05029, Republic of Korea \\ 4 Institute of Chinese Medical Sciences, State Key Laboratory of Quality Control in Chinese Medicine, \\ University of Macau, Macau, Macau SAR, People's Republic of China
}

\section{HIGHLIGHTS}

- Different nanotechnologies and nanomaterials with their efficient applications in functional food development are summarized.

- Nanotechnologies boosted the food, medicine, and biotechnology sector through enhanced food bioavailability, food processing, packaging, and preservation are also reviewed.

- This comprehensive review on nanotechnologies in food science describes the recent trend and future perspectives for future functional nanofood research and development.

\begin{abstract}
Nanotechnology is a key advanced technology enabling contribution, development, and sustainable impact on food, medicine, and agriculture sectors. Nanomaterials have potential to lead qualitative and quantitative production of healthier, safer, and high-quality functional foods which are perishable or semi-perishable in nature. Nanotechnologies are superior than conventional food processing technologies with increased shelf life of food products, preventing contamination, and production of enhanced food quality. This comprehensive review on nanotechnologies for functional food development describes the current trends and future perspectives of advanced nanomaterials in food sector considering processing, packaging, security, and storage. Applications of nanotechnologies enhance the food bioavailability, taste, texture, and consistency, achieved through modification of particle size, possible cluster formation, and surface charge of food nanomaterials. In addition, the nanodelivery-mediated nutraceuticals, synergistic action of nanomaterials in food protection, and the application of

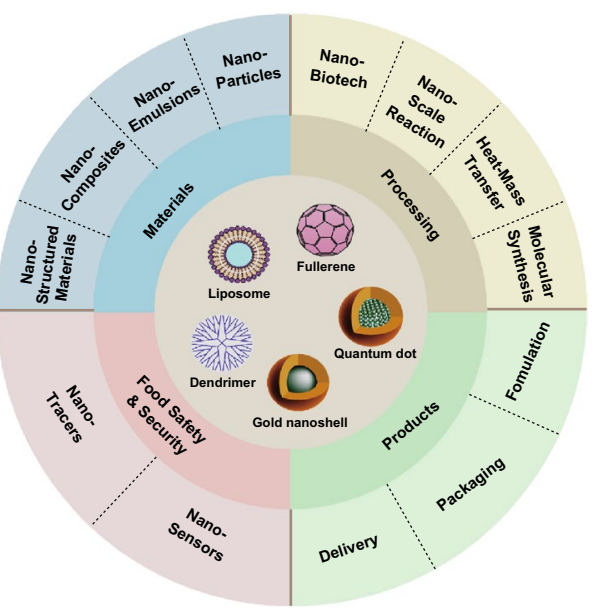
nanosensors in smart food packaging for monitoring the quality of the stored foods and the common methods employed for assessing the impact of nanomaterials in biological systems are also discussed.
\end{abstract}

KEYWORDS Nanomaterials; Functional food; Food processing; Nanodelivery; Bioavailability 


\section{Introduction}

Nanotechnology is the technology applied in the manipulation of nanomaterials for several purposes, which plays a crucial role in the food and agriculture sectors, contributes to crop improvement, enhances the food quality and safety, and promotes human health through novel and innovative approaches [1]. Owing to the unique physical, chemical, and biological properties with large surface-volume ratio as well as the altered solubility and toxicity when compared with their macroscale counterparts, engineered nanometer-sized particles have gained more attention in medicine, agro-food sectors, sewage water treatments, and other industries [2, 3]. Silver $(\mathrm{Ag})$, gold $(\mathrm{Au})$, zinc oxide $(\mathrm{ZnO})$, titanium dioxide $\left(\mathrm{TiO}_{2}\right)$, and carbon nanoparticles are manufactured as much as tenfold that of other nanomaterials in amount due to their potential antimicrobial characteristics, being used in air filters, food storage containers, deodorants, bandages, toothpastes, paints, and other home appliances [3, 4]. Besides, the potent antibiotic activity of nanosized copper oxides $(\mathrm{nCuO})$ has resulted in the wide application in commercial nano-biocide products [5]. Nanomaterials are tiny particles ranging from 1 to $100 \mathrm{~nm}$ in size, insoluble or bio-persistent in nature, synthesized through various routes, and used in numerous fields including medicine, electronics, agriculture, and food industries [6]. Different sized nanoparticles are used in nanotechnologies of food science for potential production and processing of healthier, safer, and high-quality foods (Fig. 1).

Food wastage leads to major losses in the food industry. Food and Agriculture Organization of the United Nations reported that more than 1.3 billion metric tons of consumable food is lost or wasted every year throughout the supply chain, mainly because of inferior post-harvest techniques, storage, transport facilities, and market and consumer wastage of food [7]. Apart from enhancing the food production rate, it is mandatory to tackle food wastage for the purpose to solve the food crisis caused by the emerging population and environmental issues. The major cause for food wastage is microbial contamination and food spoilage that reduces the food quality and affects food security, decreases shelf life of food products, and increases the risks of food-borne diseases [8]. In food industry, nanotechnology is applied for all practices: food production, processing, storage, and distribution (Fig. 2). It provides enhanced security by using nanosensors to detect

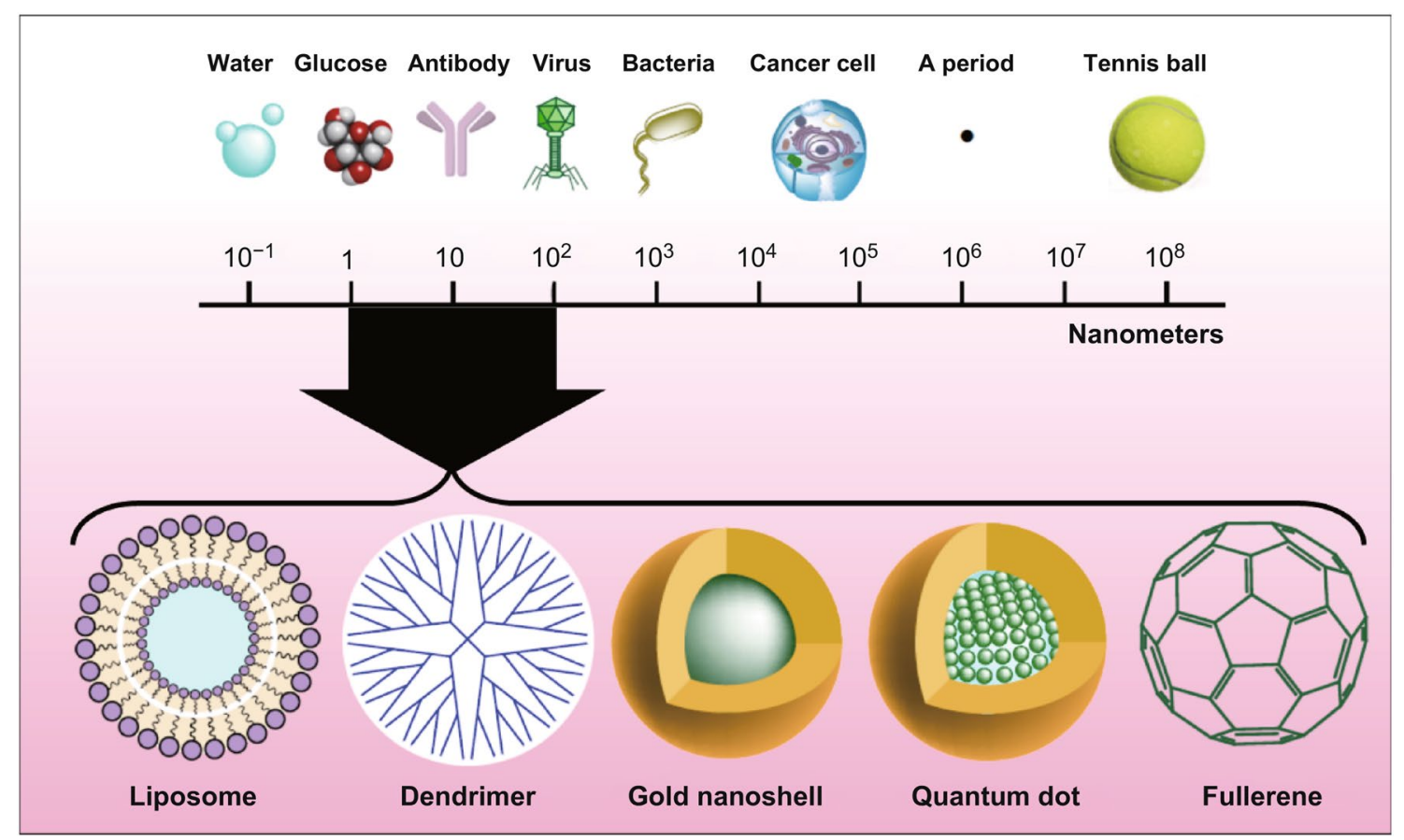

Fig. 1 Different sized nanoparticles used in nanotechnologies of food science. This figure was modified and adopted from Ref. [255] with permission 


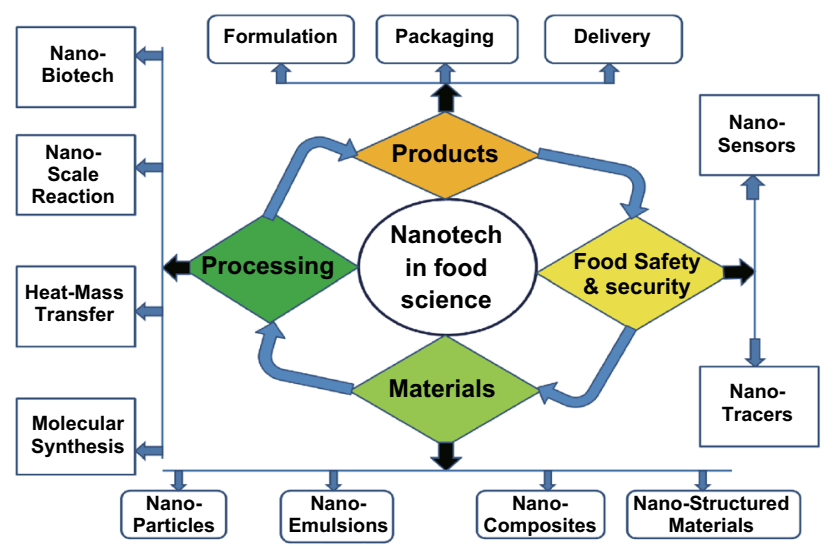

Fig. 2 Nanotechnology in food science and technology

any pathogen or containments in food. Nanotechnologyenhanced food packaging offers an improvement over conventional packaging that uses plastic barriers, and at the same time its functional components such as antimicrobial activities provide increased shelf life to the food products. It is also involved in the detection of food toxins, flavor production, and color formation [9]. Nanotechnologybased smart and intelligent systems provide localization, sensing, reporting, and remote control of food items with improved efficiency and security. Furthermore, nano-based delivery systems improve the nutraceutical values of the food components. Apart from their roles in food industry, nanomaterials also promote plant growth. For instance, $\mathrm{TiO}_{2}$ was shown to enhance the growth of many plants, gold nanoparticles increased the yield of seeds in Arabidopsis, and cellulose nanocrystals boost seed germination owing to their high water uptake potential [10].

The effective antimicrobial nature of biologically synthesized metallic nanoparticles not only controls the plant diseases, but also decreases environmental pollution. Nanomaterials, like carbon nanotubes, act as potential antimicrobial agents. Aggregates of carbon nanotubes caused cellular damage or death of $E$. coli by puncturing the cell when in direct contact with the bacterium [11]. The implementation of nano-biosensors in the detection of carcinogenic pathogens to prepare high-quality and contamination-free food has been widely reported. In this review, the potential utilization and applications of nanotechnology with different nanomaterials in food sector considering processing, preservation, storage, and security in terms of enhanced shelf life and quality are discussed. The potential applications of nanotechnology in nutraceuticals, the diagnosis of food pathogens as well as the possible harmful effects of nanotechnology in human and animal health are reviewed.

\section{Nanotechnology in Food Processing}

Nanofood refers to the food generated by using nanotechnology in processing, production, security, and packaging of food. Nanotechnology has immense potential in the postharvest food processing. It enhances food bioavailability, taste, texture, and consistency, or conceals the unpleasant taste or odor, and modifies the particle size, size distribution, possible cluster formation, and surface charge [12]. Edible nano-coatings ( $\sim \mathrm{nm}$ thin coatings) can be used in meat, fruits, vegetables, cheese, fast food, bakery goods, and confectionery products, in which they serve as gas and moisture barriers. In addition, they provide flavor, color, enzymes, antioxidants, anti-browning compounds, and a prolonged shelf life to the manufactured products. Various bakery goods, coated with edible antibacterial nano-coatings, are available $[13,14]$. Nanofilters have been used to remove color from beetroot juice while retaining the flavor and the red wine, and to remove lactose from milk so that it can be substituted with other sugars, making the milk suitable for lactose-intolerant patients. Nanoscale filters help in the elimination of bacterial species from milk or water without boiling. Nanomaterials used for developing nanosieves can be used for the filtration of milk and beer $[9,14]$.

Nanotechnology is used in the production of healthier food containing low fat, sugar, and salt to avoid food-borne diseases. It was reported that silicon dioxide $\left(\mathrm{SiO}_{2}\right)$ and $\mathrm{TiO}_{2}$ were allowed as food additives in bulk quantities (E551 and E171, respectively) [15]. The shelf life of tomato has been increased by the bionanoencapsulated quercetin (biodegradable poly-D,L-lactide), and this approach should be extended to increase the shelf life of other vegetables and fruits [16]. Nanogreen tea, Neosino capsules (dietary supplements), Canola active oil, Aquanova (micelle to enhance the solubility of vitamins (A, C, D, E, and K), beta-carotene, and omega fatty acids), Nutralease (fortifying nanocarriers to carry nutraceuticals and drugs) are the common commercialized nanotechnology-based products in the market. Similarly, fortified fruit juices, oat nutritional drinks, nanoteas, nanocapsules containing tuna fish oil in breads, and 
nanoceuticals slim shakes are few commercially available nano-processed foods in the market which are widely sold in the USA, Australia, China, and Japan [17, 18]. Nanotechnology in production of commercial nanofood products and their applications in various food science technologies are shown in Table 1.

\section{Nanotechnology for Food Packaging}

Packaging industry contributes largely to the world economy; nearly 55-65\% of $\$ 130$ billion was spent on food and beverage packaging in the USA [19]. In recent years, the application of active and intelligent packaging systems in the muscle-based food products, which are prone to contamination, has increased tremendously. The aim of packaging meat and muscle products is to suppress spoilage, bypass contamination, enhance the tenderness by allowing enzymatic activity, decrease weight loss, and retain the cherry red color in red meats [20]. The advent of nanosensors provides food spoilage or contamination alarm to the consumers by detecting toxins, pesticides, and microbial contamination in the food products, based on flavor production and color formation [21]. Most of the nanoparticles used for packaging in food industry have potential antimicrobial activity, acting as carriers for antimicrobial polypeptides and providing protection against microbial spoilage. Packaging material made of a coating of starch colloids filled with the antimicrobial agent acts as a barrier to microbes through the controlled release of antimicrobials from the packaged material [22].

Nanoparticles are used as carriers to introduce enzymes, antioxidants, anti-browning agents, flavors, and other bioactive materials to improve the shelf life even after the package is opened [23, 24]. Few metals and metal oxide nanoparticles (inorganic nanoparticles), namely iron, silver, zinc oxides, carbon, magnesium oxides, titanium oxides, and silicon dioxide nanoparticles, are widely utilized as antimicrobials and in some conditions as food ingredients [21]. Nanomaterials and their applications in food products are listed in Table 2. The production of reactive oxygen species (ROS) by $\mathrm{TiO}_{2}$ is detrimental to pathogenic microbes, making it an effective antimicrobial agent. Enhanced heat resistance, low weight, and mechanical strength, and an increased barrier against $\mathrm{O}_{2}, \mathrm{CO}_{2}$, moisture, $\mathrm{UV}$ radiation, and volatiles can be achieved with the use of nanocomposites. Nanocomposites are commonly utilized for packaging and coating purposes [25, 26]. Numerous nanoparticles such as $\mathrm{SiO}_{2}$, clay and silicate nanoplatelets, carbon nanotubes, starch nanocrystals, graphene, chitin or chitosan nanoparticles, cellulose-based nanofibers, and other inorganics are filled in a polymeric matrix, making the matrix lighter and fire-resistant with improved thermal properties and low permeability to gases [1]. Nanoparticles (100 nm or less) are included in plastics to enhance their properties. Polymer nanocomposites are thermoplastic polymers composed of 2-8\% nanoscale incorporations, such as carbon nanoparticles, nanoclays, polymeric resins, and nanoscale metals and oxides. The extremely reactive nature of nanocomposites over their macroscale counterparts is due to the high surface-to-volume ratio [27]. Silver in the silver zeolite is responsible for the antimicrobial activity via the production of ROS, and the ceramics coated with the silver zeolite are used in food preservation, decontamination of materials, and disinfection of medical products. The sustained antimicrobial performance of silver-based nanocomposite is superior to silver zeolite $[28,29]$. Utilization of carbon nanotubes facilitates the elimination of $\mathrm{CO}_{2}$ or assimilation of unpleasant flavors. Furthermore, nanoclay in the nanocomposites (bentonite), used in the production of bottles and other food packaging materials, significantly enhances the gas barrier features and thereby inhibits oxygen and moisture from diffusion, drink destabilization, and spoilage of food materials [30, 31].

The inclusion of active nanoparticles into the polymer matrices increases the performance of the food packaging material and provides functional attributes such as antioxidant, antimicrobial, and scavenging which results in the longer shelf life of the packed food products [22]. The utilization of nanocrystals developed by Nanocor (Arlington Heights, USA) in nanocomposite plastic beer bottles is to reduce the loss of $\mathrm{CO}_{2}$ and inflow of $\mathrm{O}_{2}$ into the beer bottles, like the natural biopolymer-based nanocomposites [32, 33]. The incorporation of clay nanoparticles into the ethylene-vinyl alcohol copolymer and polylactic acid (PLA) biopolymer was shown to improve the oxygen barrier and increase the shelf life of food materials [34]. The organically modified nanoclays incorporated in the polymer matrix provide mechanical strength and serve as a barrier to gases, volatiles, and moisture [35]. Interestingly, PLA bionanocomposite produced from the incorporation of nanofillers into the biodegradable polymer PLA showed more rapid biodegradation than its counterpart PLA without nanofillers. 


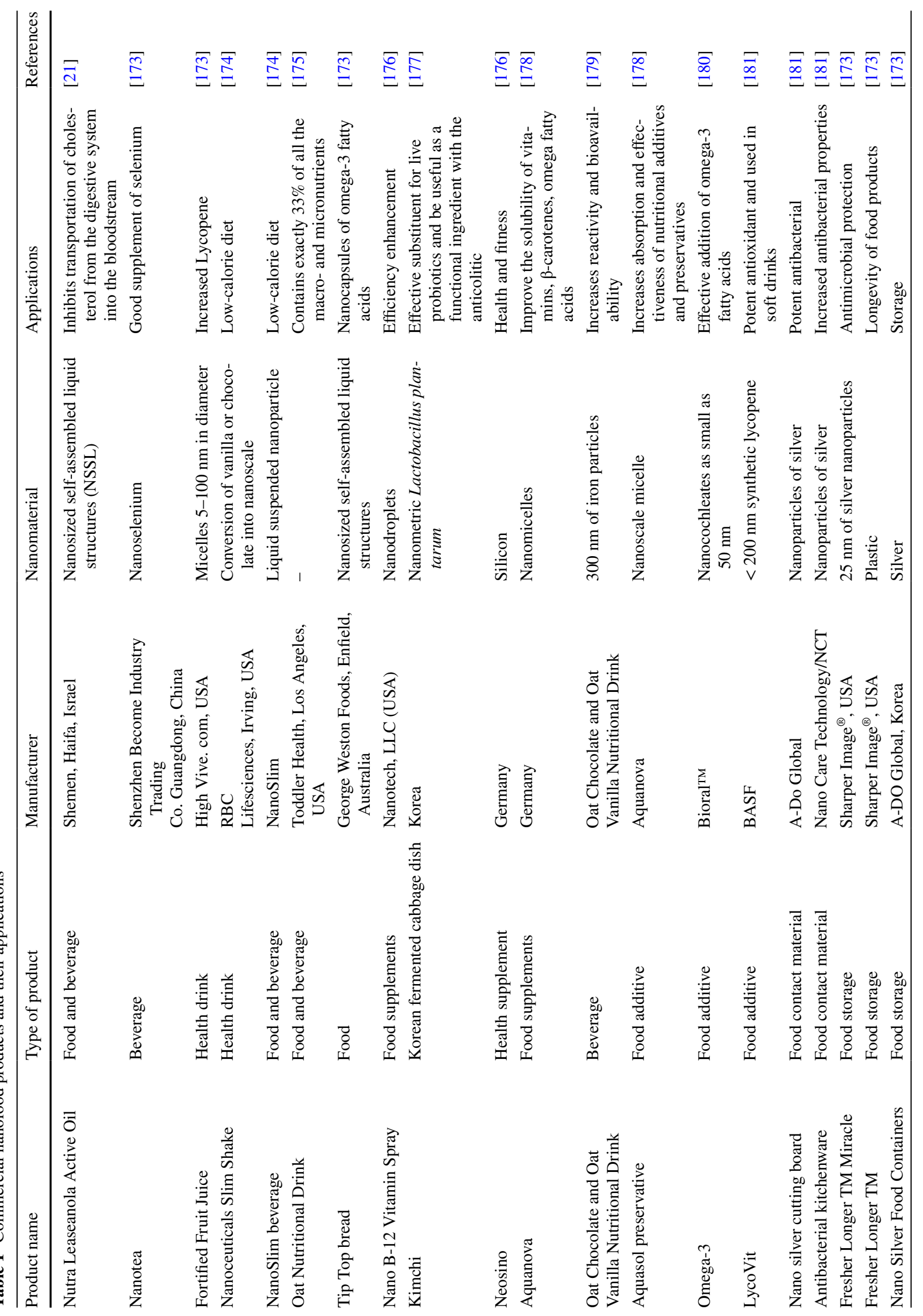









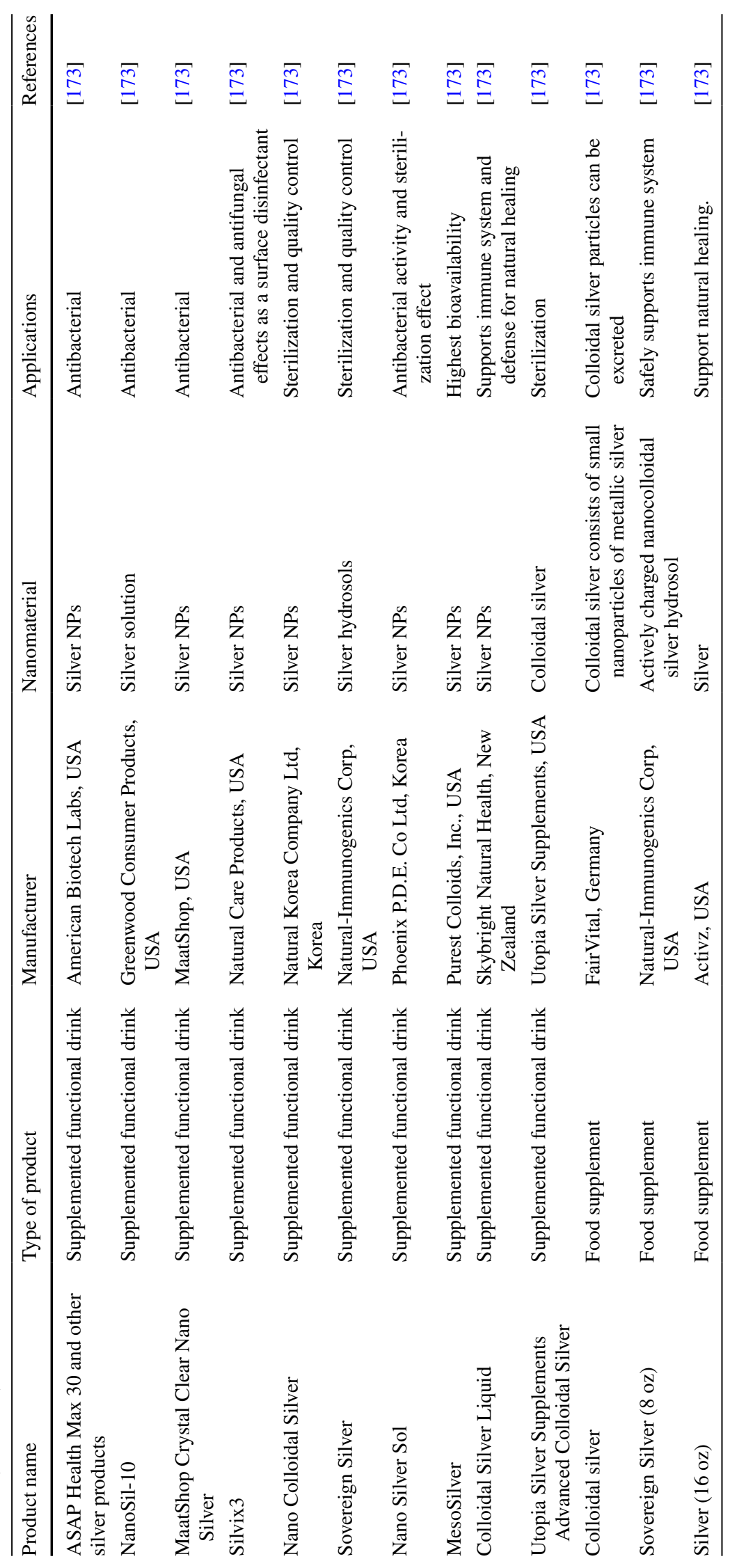


Table 2 List of nanomaterial-based biosensors with their application in food science and food nanotechnology

\begin{tabular}{|c|c|c|c|}
\hline Nanomaterials & Analyte & Samples & References \\
\hline Silicon dioxide & $\begin{array}{l}\text { Act as food colorant, hygroscopic, anticak- } \\
\text { ing, and drying agent. }\end{array}$ & Food preservation and packaging & [185] \\
\hline Titanium dioxide & $\begin{array}{l}\text { Used as whitener in dairy products (e.g., } \\
\text { milk and cheese) }\end{array}$ & Food preservation and packaging & [186] \\
\hline Zinc oxide & $\begin{array}{l}\text { Reduces the oxygen flow inside the packed } \\
\text { containers }\end{array}$ & Food preservation and packaging & [186] \\
\hline Silver nanoparticles & $\begin{array}{l}\text { Acts as antibacterial agent, absorbs, } \\
\text { and decomposes ethylene in fruit and } \\
\text { vegetables }\end{array}$ & Food preservation and packaging & {$[187]$} \\
\hline Inorganic nanoceramic & Used in cooking (frying) & Food preservation and packaging & [188] \\
\hline Polymeric nanoparticles & $\begin{array}{l}\text { Used as bactericidal and efficient delivery } \\
\text { mechanism }\end{array}$ & Food preservation and packaging & [158] \\
\hline Chitosan & $\begin{array}{l}\text { Used as coating agent for mandarin, straw- } \\
\text { berries, and fresh fruits }\end{array}$ & Anti-fungicide & [189] \\
\hline Gold nanoparticles AuNPs & $\begin{array}{l}\text { Integration of DNA or enzymes or anti- } \\
\text { bodies with Au NP } \\
\text { Pathogens } \\
\text { Glucose }\end{array}$ & $\begin{array}{l}\text { Food storage applications } \\
\text { Meat and dairy industries } \\
\text { Fruit juice }\end{array}$ & [190] \\
\hline SWCNT (single-wall carbon nanotubes) & $\begin{array}{l}\text { Integration with biomolecules } \\
\text { Fructose } \\
\text { Methyl parathion } \\
\text { and chlorpyrifos }\end{array}$ & $\begin{array}{l}\text { Wine } \\
\text { Honey } \\
\text { Phosphate-buffered solution }\end{array}$ & $\begin{array}{l}{[191]} \\
{[192]}\end{array}$ \\
\hline MWCNT (multi-walled carbon nanotubes) & $\begin{array}{l}\text { Integration biomolecules } \\
\text { Paraoxon } \\
\text { Fructose }\end{array}$ & $\begin{array}{l}\text { Food industry } \\
\text { Phosphate-buffered solution }\end{array}$ & [193] \\
\hline $\begin{array}{l}\text { CdTe QDs (cadmium telluride quantum } \\
\text { dot nanoparticles) }\end{array}$ & Integration biomolecules & Food industry & [194] \\
\hline $\mathrm{Cu}$ and $\mathrm{Au}$ NPs & Pathogens & Surface water & [195] \\
\hline $\mathrm{ZrO} 2 \mathrm{NPs}$ & Parathion & Phosphate-buffered solution & [196] \\
\hline Exfoliated graphite nanoplatelet xGnPs & Glucose & Phosphate-buffered solution & [192] \\
\hline Glyco-NPs & E. coli & Phosphate-buffered solution & [197] \\
\hline Quantum dots, QDs & Salmonella typhi & Chiken carcass wash water & [198] \\
\hline Gold nanorods & Pseudomonas & Sodium chloride & [199] \\
\hline Silica particles coated with silver shells & E. coli & Water & {$[200]$} \\
\hline $\mathrm{Au}$ NPs & $\begin{array}{l}\text { Mycobacteriumavium subsp. paratuber- } \\
\text { culosis }\end{array}$ & Milk & [201] \\
\hline CdTe QD & 2,4 D (herbicide) & Phosphate-buffered solution & [202] \\
\hline$(\mathrm{CdSe}) \mathrm{ZnS}$ core shell QDs & Paraoxon (insecticide) & $\mathrm{CH}_{3} \mathrm{OH} / \mathrm{H}_{2} \mathrm{O}(\mathrm{v} / \mathrm{v})$ solvent & [203] \\
\hline $\mathrm{Au}$ NPs & Paraoxon (insecticide) & Glycine buffer & [204] \\
\hline $\mathrm{Fe}_{3} \mathrm{O}_{4} \mathrm{MNPs}$ & Glucose & Acetate buffer solution & [205] \\
\hline CdTe QDs & Glucose & Phosphate-buffered solution & [203] \\
\hline CdSe@ZnS NPs & Maltose & Buffer solution & [206] \\
\hline Silver zeolite & Antimicrobial agent & $\begin{array}{l}\text { Preservations, disinfectors, and decon- } \\
\text { taminants }\end{array}$ & [29] \\
\hline $\mathrm{Al}_{2} \mathrm{O}_{3}, \mathrm{La}$, Nano & Water purification and soil cleaning & Oxidation of contaminants & [207] \\
\hline Colloidal metals & Food supplements & Enhanced uptake & [208] \\
\hline Graphene & Nanoplate-based nanocomposites & Detects contaminants in food & [209] \\
\hline Cellulose nanocrystals & Biocompatible high water uptake & Food packaging & [210] \\
\hline Magnetic nanoparticles & Large specific surface area & Pathogen monitoring & [211] \\
\hline Carbon nanotubes & $\begin{array}{l}\text { Optical, electrical, mechanical, and ther- } \\
\text { mal conductivity }\end{array}$ & $\begin{array}{l}\text { Food inspection and vacuum proof food } \\
\text { packaging }\end{array}$ & [16] \\
\hline
\end{tabular}


Table 2 (continued)

\begin{tabular}{|c|c|c|c|}
\hline Nanomaterials & Analyte & Samples & References \\
\hline Allyl isothiocyanate and carbon nanotubes & Antimicrobial packaging & $\begin{array}{l}\text { Enabled effective storage of shredded } \\
\text { cooked chicken meat }\end{array}$ & [212] \\
\hline Nanolaminates & Food-grade film & $\begin{array}{l}\text { Improve the texture properties of foods } \\
\text { and serve as carriers }\end{array}$ & [113] \\
\hline
\end{tabular}

Mechanical, thermal, and barrier properties of the packaging material have been significantly increased by the inclusion of polymer-clay nanocomposites [36]. Obstruction of oxidation, and regulations of moisture migration, respiration rate, microbial growth, volatile flavor, and aromas are greatly influenced by the application of nanotechnology in the packaging industries [19].

Potential antimicrobial activities were reported for the chitosan-based nanocomposite films, particularly silver-containing nanocomposites [37]. Garlic essential oil filled in the PEG-coated nanoparticles can be utilized for the restriction of store-product pests [38]. The shelf life of the food product has been increased efficiently by applying phytoglycogen octenyl nanoparticles included with the $\varepsilon$-polylysine [39]. Application of silicate nanoparticles in food packaging acts as a barrier to gases or moisture and thus decreases food spoilage and drying [40]. Water-based nanocomposites forming 1-2- $\mu \mathrm{m}$ nano-coatings on food packaging materials act as a barrier to oxygen. Nanoemulsions are used in food packaging and decontamination of food packaging equipment. Glycerin included with nanomicelle-based products eliminates pesticide residues from fruits and vegetables and oil/dirt from cutlery. The addition of nanoemulsified bioactive and flavors to beverages does not affect the product appearance [37, 41]. Different food pathogens like gramnegative bacteria are significantly controlled by nanoemulsions. Active and intelligent packaging systems are widely used. Various nanoformulation approaches and their applications in food products are presented in Table 3.

\subsection{Active Food Packaging Systems}

The active packaging systems consist of moisture regulating agents, $\mathrm{CO}_{2}$ scavengers and emitters, oxygen scavengers, and antimicrobials. Active packaging systems are developed depending on the purpose of the storage [42]. For example, overwrap packaging systems are used for short-term chilled storage, while modified atmosphere packaging (MAP) systems, vacuum packaging, MAP systems utilizing $100 \% \mathrm{CO}_{2}$, and bulk gas flushing are employed for long-term chilled storage. Low-density polyethylene (LDPE) and polypropylene (PP), the commercially used polymeric films for packaging, are inert, are hydrophobic, and have less surface energy [20]. Surface modifications with functional properties and polar groups for the inclusion of antimicrobial substances are essential to eliminate food spoilage [43]. Factors such as lipid oxidation, dehydration, discoloration, and loss of aroma should be considered in the case of processed meats; additives are included in the packaging systems to extend and maintain the shelf life of meat products [20]. Potential for the development of metallic-based nanocomposites in active food packaging is described in Fig. 3.

The MAP is one of the important packaging systems widely operated for the distribution, storage, and maintenance of meat products under cold condition [20]. MAP technology enhances the shelf life and quality of the meat products by replacing the air compassing the meat products with formulated gas mixtures. In general, the non-inert gases such as $\mathrm{O}_{2}$ and $\mathrm{CO}_{2}$ are used in the MAP technology and their profiles change over time, influenced by factors like the type of product, respiration, materials used for packaging, size of the pack, storage conditions, and package integrity [43]. The uniform dispersion of clay nanoparticles on the transparent plastic film produced by Chemical giant Bayer (Leverkusen, Germany) prevents $\mathrm{O}_{2}$, $\mathrm{CO}_{2}$, and moisture from reaching fresh meats and other foods. Several patents on the applications of nanomaterials in the food packaging have been filed in the USA, Europe, and Asia, and most of them report the utilization of nanoclays and nanosilver [44]. The inclusion of allyl isothiocyanate and carbon nanotubes into the active packaging systems decreases microbial contamination and color changes, regulates oxidation, and helps in the storage of shredded, cooked chicken meat for 40 days [42]. 
Table 3 Different types of nanoformulations and their applications in food industries

\begin{tabular}{|c|c|c|c|c|}
\hline Nanostructured materials & Nanoparticles & Methods & Applications & References \\
\hline Low-density lipoproteins & Fish oil & Microencapsulation & $\begin{array}{l}\text { Food additives-mask odor of } \\
\text { tuna fish oil }\end{array}$ & [213] \\
\hline $\begin{array}{l}\text { Biopolymers (proteins or poly- } \\
\text { saccarides) }\end{array}$ & Micelles & Microemulsions & $\begin{array}{l}\text { Produce glycerides in food } \\
\text { products }\end{array}$ & [214] \\
\hline $\begin{array}{l}\text { Biodegradable biopolymeric } \\
\text { NPs }\end{array}$ & Polylactic acid & Encapsulation & $\begin{array}{l}\text { Encapsulate and deliver drugs, } \\
\text { vaccines, and proteins }\end{array}$ & {$[176]$} \\
\hline Liposomes & Phospholipids & Encapsulation & $\begin{array}{l}\text { Integrate food antimicrobials } \\
\text { for the protection of food } \\
\text { products }\end{array}$ & [215] \\
\hline Liposomes & Nanoliposomes & Nanoencapsulation & $\begin{array}{l}\text { Lipid-based carriers for anti- } \\
\text { oxidants }\end{array}$ & [216] \\
\hline $\begin{array}{l}\text { Food components integrated } \\
\text { with droplets }\end{array}$ & Colloidal dispersions of droplet & Nanoemulsions & $\begin{array}{l}\text { Flavored food products. Milk } \\
\text { fortified with vitamins, min- } \\
\text { erals, and antioxidants }\end{array}$ & [129] \\
\hline $\begin{array}{l}\text { Polymer matrices reinforced in } \\
\text { the nanofillers }\end{array}$ & $\begin{array}{l}\text { Nanoclays, nanooxides, carbon } \\
\text { nanotubes, and cellulose } \\
\text { microfibrils }\end{array}$ & Nanocomposites & Biodegradable packaging & {$[176]$} \\
\hline Fine emulsion droplets & $\begin{array}{l}\text { Reducing the size of fat } \\
\text { globules }\end{array}$ & $\begin{array}{l}\text { Homogenization or micoflu- } \\
\text { idization }\end{array}$ & $\begin{array}{l}\text { High-pressure homogeniz- } \\
\text { ers in producing finer milk } \\
\text { emulsions }\end{array}$ & {$[176]$} \\
\hline $\begin{array}{l}\text { High-intensity ultrasound } \\
\text { waves }\end{array}$ & Oil and water nanoemulsions & Ultrasound emulsification & $\begin{array}{l}\text { To change the characteristics of } \\
\text { treated matters }\end{array}$ & [179] \\
\hline PLA NPs & Curcumin and quercetin & Encapsulation & As bio-stabilizer & [107] \\
\hline PLA NPs & Leaf extract & Encapsulation & Developed a greener approach & [107] \\
\hline Stevioside $n p$ & PEG-PLA nanoparticles & Nanoencapsulation & $\begin{array}{l}\text { Developed an antidiabetic } \\
\text { nutraceutical }\end{array}$ & [217] \\
\hline Podophyllotoxin and etoposide & $\begin{array}{l}\text { Poly-d,l-lactide nanoparticles } \\
\text { (PLA NPs) }\end{array}$ & Encapsulation & Anticancer activity & [218] \\
\hline BSA NPs & $\begin{array}{l}\text { Tea polyphenols, catechin, and } \\
\text { epicatechin }\end{array}$ & $\begin{array}{l}\text { Encapsulation } \\
\text { Nanoformulations }\end{array}$ & $\begin{array}{l}\text { Enhance stability and bioavail- } \\
\text { ability } \\
\text { Antioxidant potential }\end{array}$ & [110] \\
\hline Canola oil & Vitamin E & Nanoemulsions & $\begin{array}{l}\text { Nutritional benefits and oxida- } \\
\text { tive stability }\end{array}$ & [219] \\
\hline
\end{tabular}

\subsection{Smart/Intelligent Food Packaging Systems}

Smart packaging systems respond to environmental stimuli by repairing or alerting the consumer regarding the contamination or the presence of pathogens. Nanoparticles are used in the development of nanosensors to detect food contaminants. Custom-made nanosensors are used for food analysis, detection of flavors or colors, drinking water, and clinical diagnosis [45]. Application of nanosensors in food packaging aids in tracing the physical, chemical, and biological modifications during food processing. Specifically designed nanosensors and nanodevices utilized in smart packaging help in detecting toxins, chemicals, and food pathogens [46]. The intelligent packaging systems with sensors and indicators are also used to track and give information regarding the quality of the packaged foods during storage and transport. Various functional nanomaterials, used as nanosensors and active packaging materials that provide significant mechanical and barrier properties, are potential targeted nutrient delivery systems [47]. With the advent of sensors, sensor-based indicators for integrity, freshness and time-temperature monitoring and radio frequency identification were used in the meat industry [20]. It has been reported that smart or intelligent packaging retains the food quality during distribution. The response to modifications associated with the internal or external environmental stimuli is registered by the specific sensor. Integrity (package integrity determination), freshness 


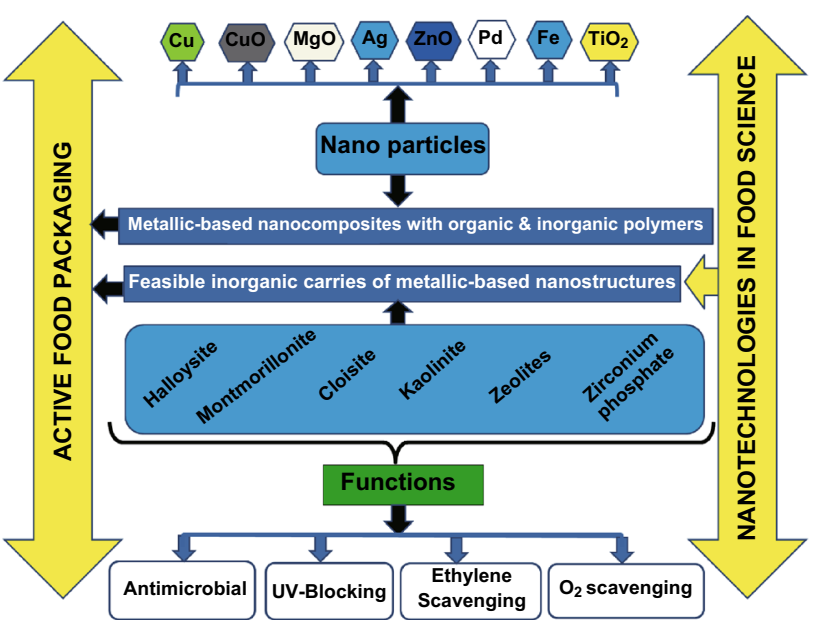

Fig. 3 Potential for the development of metallic-based nanocomposites in active food packaging

(quality of the packaged products), and time-temperature (time and temperature dependent changes) indicators are commonly used in the food packaging applications. These indicators are monitored throughout the production and distribution chain in order to maintain the quality and enhance the shelf life of products. Barcodes developed with the help of nanoparticles, called nanobarcodes, can be used as ID tags [48].

Nanosensor application in packaging provides details of enzymes generated during the degradation of food compounds that makes food unsuitable for human intake. Packaging improves the shelf life of the food products by preventing air and other enzymes from entering and decreases the use of artificial preservatives. It also helps in the elimination of the ripening hormone known as ethylene to enhance the shelf life of food products [49]. The nanosensors in the smart packaging systems are used for the detection of gases, chemical contaminants, aromas, temperature and light intensity, pathogens, or the products of microbial metabolism [50]. Analytical techniques such as GC/MS, portable headspace $\mathrm{O}_{2}$, and $\mathrm{CO}_{2}$ gas analyzers are available to investigate the gas phases in the MAP products. However, these methods have certain demerits; optical sensor-based approaches are more effective than these methods in real-time packaging processes or large-scale usage [20,43]. Food rotting is a major concern in the food industry; it is caused mainly by bacteria that result in the release of unpleasant odor, which may be difficult to detect with human nose, and sometimes rotting food may lead to poisoning. In order to detect the odors generated due to food poisoning, highly sensitive biosensors are required [51]. For example, the device electronic nose functions like a human nose which utilizes sets of chemical sensors attached to a data processing system. Methods to determine chemical and physical characteristics of pears and fruit odors using the electronic nose signal have been reported [52]. Interestingly, electronic nose can be used to detect variations in the aroma of strawberry fruit, osmotic dehydration, and the quality of milk during processing. This device is used for a highly accurate determination of volatiles and monitoring the quality control processes in food industry. Nanosensors were applied in the European project GOODFOOD (2004-2007) for food safety and quality control applications [53].

\section{Mechanism of Nanoparticle Activity}

Common factors such as product nature (formulation), processing conditions (intrinsic factors), type of package and storage and distribution crucially affect the shelf life of a food product [54]. Intrinsic factors like water activity, $\mathrm{pH}$, microbes, enzymes, and the level of reactive compounds can be regulated by using specific raw materials and ingredients and appropriate processing parameters. Temperature, total pressure, light, partial pressure of various gases, relative humidity, and mechanical stress (human handling) are the common extrinsic factors that influence the rate of degradation reactions during food material storage [55]. It is worth noting that the microbial growth mostly occurs on the surface of the perishable foods, including muscle-based foods, and therefore, utilization of antimicrobial packaging efficiently controls the microbial growth compared to the application of antimicrobials as food additives. Furthermore, antimicrobial packaging effectively interacts with the food product as well as the environment [56]. Nanoparticles are widely used in the packaging systems due to their potential antimicrobial properties. Most of the nanoparticles produce ROS, thus damaging the microbes present on the surface of food and packaging materials. Antimicrobial nanoparticles, namely $\mathrm{Cu}, \mathrm{CuO}, \mathrm{MgO}, \mathrm{Ag}, \mathrm{ZnO}, \mathrm{Pd}, \mathrm{Fe}$, and $\mathrm{TiO}_{2}$, or nanoemulsions/nanoencapsulations enclosing natural antimicrobial substances that can be adhered to via electrostatic, hydrogen bonding, and covalent interactions are developed to produce antimicrobial packaging systems. Several chemical modifications and deposition processes are being used 
for the attachment of silver NP onto the surface of the plastic substrate that facilitates slower release of silver ions to reduce their inclusion in the food [43].

The potential surface charge of engineered water nanostructures (EWNS) can deactivate Salmonella enterica, Escherichia coli, and Listeria innocua effectively on the surface of stainless steel and on tomato without influencing the sensory quality of food, operating via ROS production. The degradation of EWNS results in the formation of water vapor, hence lowering the risk of hazardous environmental problems [57]. The inorganic $\left(\mathrm{ZnO}, \mathrm{TiO}_{2}\right.$, and $\left.\mathrm{Ag}\right)$ and organic (chitosan and essential oil) nanomaterials are also used for food product preservation. Since polymer matrices control the release of active components, they regulate the function of nanocomposites. Polymers such as polyolefins, nylons, ethylene-vinyl acetate (EVA) copolymer, polyethyleneterephthalate (PET), polystyrene (PS), polyamides, and polyimides have been used for nanocomposite production [58]. For example, silver NPs immobilized in cellulose and collagen sausages casings showed potential bactericidal activity against E. coli and Staphylococcus aureus, but they were not harmful to humans and the environment [55]. Such superior antimicrobial activity against $E$. coli and $S$. aureus had been demonstrated with silver-polyamide nanocomposites, where the antimicrobial efficiency lasted for 28 days. The antimicrobial nature of the nanocomposite is significantly affected by the characteristics of the polymer and NP [59]. Various types of nanoparticles that could help to prevent, detect, or treat bacterial infections like silver, gold, and tiny magnetic particles help to trigger or capture bacterial pathogens and help to prevent bacterial spread in hospitals and human body, providing an attractive way to rapidly detect bacterial biomolecules in a point-of-care compatible setting $[43,59]$. The details about different nanotechnologybased solutions that could help to prevent, detect, or treat bacterial infections are presented in Fig. 4.

The LDPE films coated with silver NPs using a layerby-layer method have a significant antimicrobial potential against S. aureus (gram-positive) and Pseudomonas fluorescens (gram-negative) [60]. Similarly, significant antimicrobial functions against L. monocytogenes, E. coli O157: $\mathrm{H} 7$, S. aureus, and S. typhimurium were observed in the chitosan-silver nanocomposite prepared by the solvent casting method [37]. ZnO-encapsulated halloysite-polylactic acid nanocomposite comprising packaging films exhibited enhanced mechanical and antimicrobial activities [61].
Pathogenic bacteria species such as E. coli, Listeria monocytogenes, and $P$. aeruginosa residing in the meat products were deactivated by the $\mathrm{LDPE} / \mathrm{ZnO}^{+} \mathrm{Ag}$ nanocomposites. In addition, the application of these nanocomposites enhanced the shelf life of the chicken breast fillets and slowed down the bacterial growth and lipid oxidation. It was reported that the improved quality of lemon with lower total soluble solids and punch force, enhanced titratable acid, firmness, and peel shear forces were found when they were coated with the chosen clay nanocomposites during cold storage [62].

The storage conditions and duration also influence the antimicrobial activities of the nanocomposite films. For example, the stability and antimicrobial activity of pullulan films incorporated with NP (silver or ZnO NPs) and oregano or rosemary essential oils were studied at various temperatures $\left(4,25,37\right.$, and $\left.55^{\circ} \mathrm{C}\right)$ for 7 weeks against the common food pathogens such as L. monocytogenes and S. aureus [63]. Their results illustrated that the antimicrobial potential of the pullulan nanocomposite films was maintained at low temperature $\left(<25^{\circ} \mathrm{C}\right)$, and reduced greatly at $>25^{\circ} \mathrm{C}$. Some studied showed that the migration of $\mathrm{Ag}$ from the $\mathrm{Ag} /$ PVC films to the chicken meat was least $(8.85 \mathrm{mg} / \mathrm{kg}$ or $0.84 \mathrm{mg} \mathrm{dm}^{-2}$ ), below the legal migration limits provided by the European Union for plastic films [64]. Food packaging with low silver concentration, having an enhanced and stable bioavailability is a challenge for the application of silver in food packaging. The citrate-mediated silver complex is the most commonly used standardized silver formulation for antimicrobial purposes [65].

\subsection{Antimicrobial Properties of Nanoparticles}

Several nanoproducts are available in the market to control the microbial growth. For instance, the four crucial food-related pathogens such as E. coli O157: H7, S. typhimurium, Vibrio parahaemolyticus, and L. monocytogenes were effectively inhibited by the nanosilver product known as NanoCid ${ }^{\circledR}$ L2000 (Nano Nasb Pars Company, Tehran, Iran) [66]. Nanotechnology Consumer Product Inventory has listed many nanomaterial-related antimicrobial disinfectants. Most of the antimicrobial products found in the list contain nanosilver as the main antimicrobial agent [67]. The antibacterial activity of silver nanoparticles alone and the silver NP embedded in the carboxymethylcellulose film showed that AgNPs embedded in the carboxymethylcellulose film were 


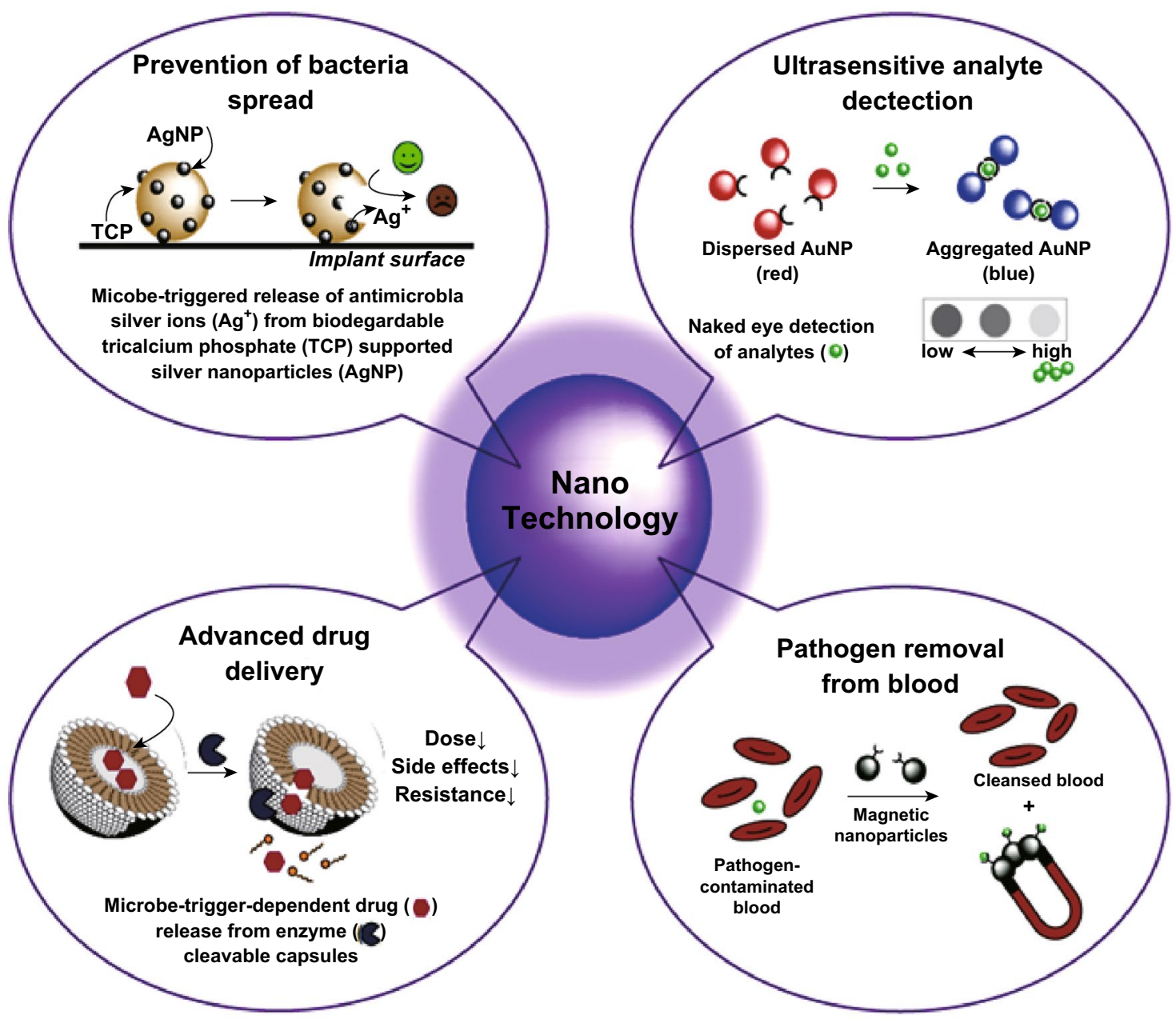

Fig. 4 Examples of nanotechnology-based solutions for detection and prevention of microbial infections. This figure was modified and adopted from Ref. [256] with permission

more potent as bactericidal than the AgNPs alone, which was suggested that antibacterial activity of AgNPs can be used food packaging [68]. Nanoengineered surfaces (antimicrobial coatings) are one of the efficient agents to suppress the growth of biofilms and enhance the quality and safety of the food. The nanoscale silver, $\mathrm{TiO}_{2}$, and $\mathrm{ZnO}$ or nanoscale topography is used for surface cleaning in the food industry. The biocontamination problems existing in poultry farming, food processing, and food transportation were effectively controlled by the UV-C ultraviolet light-activated $\mathrm{TiO}_{2}$ [69]. The pathogen transmission is mainly through air and may be involved in poultry meat contamination at different stages of slaughtering and processing [50]. The incorporation of microbicidal materials such as silver and other metals in the nanofiber mats revealed a significant antimicrobial potential
[69]. Nanoenabled membranes, nanophotocatalysts, and nanoadsorbents are used for the purification of water in the wastewater treatment [70].

\subsection{Synergistic Antimicrobial Effects of Nanoparticles}

The combinatorial use of two or more nanoparticles provides a synergistic effect exhibiting potent antimicrobial activity compared to a single nanoparticle. Silver NPs combined with titanium dioxide and carbon nanotubes effectively combat E. coli and Bacillus cereus spores, respectively [71]. B. cereus spores present on the surfaces of aluminum and polyesters were destroyed by the silver-doped $\mathrm{TiO}_{2} \mathrm{NP}$. The molds and airborne bacteria caught in the air filters are 
destroyed by the silver-doped $\mathrm{TiO}_{2} \mathrm{NP}$ [72]. Enhanced antimicrobial activity against $E$. coli and $S$. aureus was achieved by the stabilization of silver NP with SDS or PVP. Silver NP coatings have been used on the surfaces of refrigerators and storage containers [73]. Several food-related pathogens, such as Vibrio parahaemolyticus, Salmonella choleraesuis, and Listeria monocytogenes, are shown to be affected by the UV-activated $\mathrm{TiO}_{2} \mathrm{NP}$ Photoactivation of $\mathrm{TiO}_{2}$, reportedly caused biocidal activities against toxic food microbes $[74,75]$.

\subsection{Synergistic Antimicrobial Activity with Natural Derivatives}

Several studies have shown the synergistic antimicrobial activities of various nanoparticles (silver, gold, zinc, chitosan, platinum, iron, copper, carbon nanotubes) with the essential oils (natural derivatives) [76]. Researchers have formulated an essential oil (EO) droplet emulsified with gold NP; also they utilized NP for the encapsulation of peppermint EOs and cinnamaldehyde [77, 78]. Similarly, thymols containing EO of Lippia sidoides were nanoencapsulated in the chitosan-gum NPs and are used in chemical, pharmaceutical, and food industries [79]. Magnetic nanofluid was produced by fusion of EOs and iron oxide NPs [80]. Oregano EO nanoencapsulated with the chitosan NPs was studied for its antimicrobial activity as well as the releasing pattern of Eos [81]. The antimicrobial activity of thymol was increased when encapsulated with the zein-sodium caseinate NPs [82]. The antibacterial and antifungal activity of the EOs is increased through nano-complex of various types of NPs. The eugenol and cinnamaldehyde incorporated in the poly (D,L-lactide-co-glycolide) (PLGA) NPs were shown to have potent biocidal activity against Salmonella and Listeria [83]. Similarly, the combinatorial preparation of liposomebased NP and Origanum dictamnus essential oil was highly effective in controlling gram-positive and gram-negative bacteria [84]. Several essential oil derivatives of Santolina insularis such as $\gamma$-terpinene, carvacrol, p-cymene, thymol, and their combination with phosphatidylcholine liposome NPs were prepared by researchers, and they have been effective in controlling the growth of microbes [85].

The researchers reported that the encapsulation of essential oil derivatives such as thymol and carvacrol within the zein nanoparticles through liquid-liquid dispersion method demonstrated a strong antioxidant and antimicrobial activity against $E$. coli. Nanoencapsulation enhances the activity of essential oil against microbes, and the polymeric nanoparticles, liposomes, and nanoemulsions are employed for this purpose; this can be used to regulate the release of drug molecule [86, 87]. Potential biocidal activity of EO encapsulated by chitosan/cashew gum nanoencapsulation was found against Stegomyia aegypti larvae due to the slow and sustained release [88]. The gram-positive bacterial growth was effectively suppressed by the thymol encapsulated in zein nanoparticle compared to thymol only [89]. Carvacrol, a monoterpenic phenol produced by aromatic plants, increased antimicrobial activity when nanoencapsulated with polylactic glycolic acid [90]. The gold nanoparticles linked with the vancomycin substituent showed more toxicity toward vancomycin-resistant bacteria [91]. Phytoglycogen NP coupled with nisin showed improved antimicrobial action against $L$. monocytogenes [92]. The application of pullulan film containing essential oils ( $2 \%$ oregano, $2 \%$ rosemary) and NPs (100 nm Ag, $110 \mathrm{~nm} \mathrm{ZnO)} \mathrm{to} \mathrm{fresh}$ turkey, raw beef, or processed turkey deli meat resulted in the suppression of L. monocytogenes, S. typhimurium, S. aureus, and E. coli 0157:H7 for more than 2 weeks when vacuum-packaged and stored at $4{ }^{\circ} \mathrm{C}$ [93]. PLA/ $\mathrm{CEO} / \beta-\mathrm{CD}$ nanofilms were developed by the inclusion of cinnamon EO- $\beta$-cyclodex trin inclusion complex $(\mathrm{CEO} / \beta-$ $\mathrm{CD}-\mathrm{IC}$ ) into the PLA nanofibers using electrospinning technique and showed potential antimicrobial functions against $S$. aureus and $E$. coli. In addition, the shelf life of fresh pork was increased to 8 days compared to control samples which had a shelf life of 3 days [94]. Nanoencapsulation of essential oil enhanced their physical stability and bioactivity, reduced the volatility and toxicity, and protected it from environmental interactions with oxygen, light, $\mathrm{pH}$, and moisture [95]. Therefore, the combination of essential oils and nanoparticles significantly increased the antimicrobial properties as they complemented each other against various pathogens; this would be an ideal strategy to constrain the multidrug resistant microbes (MDR). The emergence of MDR pathogens results in increased rate of morbidity and mortality, emphasizing the need for alternative natural drugs. Moreover, application of nanotechnology to the natural drug product formulation may ensure slow and sustained release of drugs to combat MDR microbes [76-80]. 


\section{Applications in Nutraceutical Delivery and Bioavailability}

Bioactive substances present in food provide immunity and protect against diseases. Although most of the food items possessed higher concentrations of bioactive molecules, their potency was low. It is mainly due to low bioavailability, lower solubility, and stability in the gut, decreased permeability, and retention time in the intestinal tract [96]. Nanomaterials usually consist of a wide surface area per unit mass and decreased particle dimension which enhances the biological activity, bioavailability, and solubility of the encapsulated food materials [16]. Nanosized iron and iron/ zinc materials used in the nutraceutical deliveries enhanced the bioavailability and reduced the color changes in the final products. The bioavailability of most of the vitamins (A, D, and E) and bioactive compounds such as curcumin, carotenoids, conjugated linoleic acids, coenzyme $\mathrm{Q}_{10}$, and $\omega$-30 fatty acids is low or unstable after intake [97]. Low bioavailability is due to the physicochemical and physiological parameters such as bioaccessibility, absorption, and transformation. In general, the low bioavailability, solubility, and stability of most of the bioactive molecules such as antioxidants, vitamins, micronutrients, polyphenols, carotenoids, and food ingredients can be enhanced with the help of nanotechnology specifically with nanoformulations [16]. Most of the biologically active substances used in treatment of diseases are hydrophobic in nature having least bioavailability. Nanotechnology-based delivery systems are used to enhance the bioavailability and targeted delivery of natural bioactive compounds (Fig. 5).

Nanoparticles are also made up of natural food-grade macromolecules such as proteins, surfactants, polysaccharides, lipids, and phospholipids. Composite nanoparticles are produced by different combinations of these food-grade ingredients, such as lipid core with a protein referred to as "nanoemulsions" and lipid droplets inserted in the biopolymer microspheres [95]. The efficiency, utilization, and stability of the bioactive food materials can be enhanced with the help of these food-grade nanoparticles due to their encapsulating nature, protection, and release of the bioactive food constituents [98]. Nanonutraceuticals are a combination of nutrition and pharmaceuticals in which the dietary supplements, bioactive substances, functional foods, and herbal products are produced via nanoformulation approach [21]. Different methods were employed for the delivery of nutraceuticals. Nanotubes, nanofibres, fullerenes, nanosheets, nanowhiskers are delivered via various vehicles such as liposomes, cubosome, microemulsions, solid lipid nanoparticles (SLNs), biopolymeric nanoparticles, nanosensors, monolayers, microgels, and fibers [99]. It is crucial to understand the advantages and the significant toxicity of nanocarrier systems in food products. For development of effective micronutrient delivery system for food manufactures, a great advancement in design and fabrication of various food-grade nanoparticles is done by recently with the addition of notable applications [100]. Colloidal delivery-based foods (excipient foods) can improve the bioavailability of the

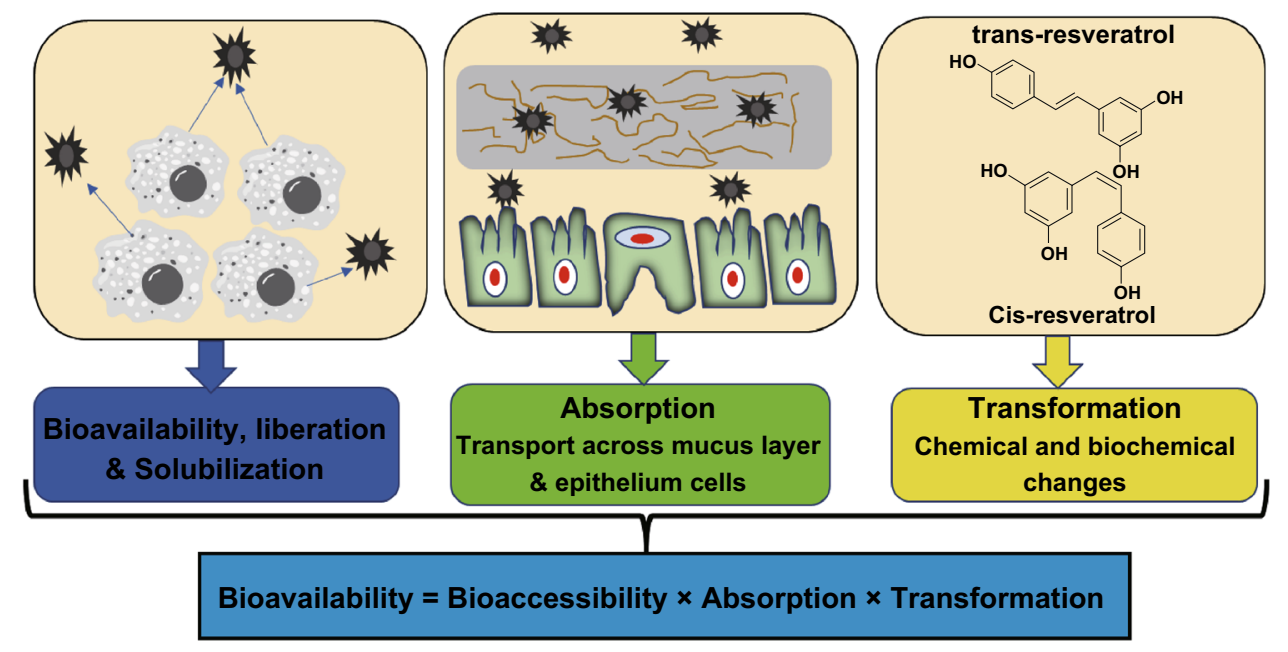

Fig. 5 Oral bioavailability of bioactive compounds controlled by three major steps: bioaccessibility, absorption, and transformation. This figure was modified and adopted from Ref. [257] with permission 
food, although they do not possess any biological activity themselves. The absorption of the bioactive agents into the systemic circulation increases, resulting in enhanced bioactivity while providing powerful health benefits. In order to enhance the bioaccessibility, absorption, or transformation profiles of bioactive compounds in the gastrointestinal tract (GTI), the composition and structure of excipient foods are specifically designed [101, 102]. There are a number of nanoparticle-based delivery systems to improve the bioavailability of the food with suitable encapsulation of micronutrients presented in Fig. 6. The applications of nanotechnology in nutraceuticals and pharmaceuticals which was discussed by many researchers in their studies are shown in Table 4 .

\subsection{Nanoemulsions}

Nanoemulsions are a colloidal particulate system with oil-inwater emulsions characteristics having a very small droplet size that varies from 10 to $1000 \mathrm{~nm}$ and containing solid spheres with amorphous and lipophilic surfaces. The nanoemulsions act as excellent carriers for various bioactive compounds with enhanced properties compared to conventional emulsions, providing with excellent properties like high optical clarity, physical stability, and enhanced bioavailability [103]. The small size of nanoemulsions helps to produce or have large surface area which can be very important for strong interaction with various bioactive compounds transported in the gastrointestinal tract. Also, the nanoemulsions show higher digestion rate compared to conventional emulsions as they are having more binding sites available amylase and lipase digestive enzymes in the gastrointestinal tract [104]. Moreover, these nanoemulsions



Fig. 6 Examples of effective micronutrient delivery system for food manufactures. This figure was modified and adopted from Ref. [101] with permission are significantly helped in rapid transfer of naturally occurring hydrophobic bioactive compounds present in functional foods into the oil droplets. Various functional foods are the types of foods which significantly help to produce energy and ameliorate the human health problems [103]. Some examples of functional food products which are already available for human beings are cereals with vitamins, minerals and $\omega$ - 3 fatty acids, curds or yogurts with probiotics, milk products fortified with vitamin $\mathrm{D}$, fruit juices enriched with various metal ions like iron and calcium, and breads fortified with phytosterols [105]. The concept of development of functional or healthier food product has gained more importance to optimize and enhance various natural bioactive compounds as food for amelioration of intrinsic health properties and bioavailability. In this context, excipient foods have been introduced as foods that are able to improve the bioactivity of foods co-ingested with them (Fig. 7) [102, 106]. The nanoemulsion-based approach effectively increases bioavailability of biologically active compounds as their structures, compositions, and properties can be regulated. Emulsion-based systems are prepared from the emulsifier-coated oil droplets dispersed in water phase. The conventional emulsion-based systems are larger in size (oil in water, $d>100 \mathrm{~nm}$ ) while the latest nanoemulsions are smaller in size $(d<100 \mathrm{~nm})[24,96]$. The nonpolar domains containing a mixed micelle phase are larger in number and harbor all released hydrophobic bioactive compounds, thus enhancing their bioaccessibility [97]. The inclusion of isolated bioactive compounds into the emulsion-based delivery systems leads to enhanced bioavailability. However, the enhanced bioavailability of bioactive compounds present in whole foods can be achieved by incorporating them into emulsion-based excipient systems (EES) [96, 97]. Polyphenols are the naturally derived secondary metabolites possessing various health benefits. The stability and oral bioavailability of the epigallocatechin gallate and curcumin were enhanced by the nanoemulsion method, and the nanoemulsion was used to enhance the yellow color pigment in turmeric [104]. The major applications of nanoemulsions include curing and treatment for enzyme replacement therapy in the liver, infection of the reticuloendothelial system, cancer prevention, and vaccination [103].

\subsection{Nanoencapsulation}

Encapsulation of bioactive nutraceutical molecules using nanoformulations increased their bioavailability and 







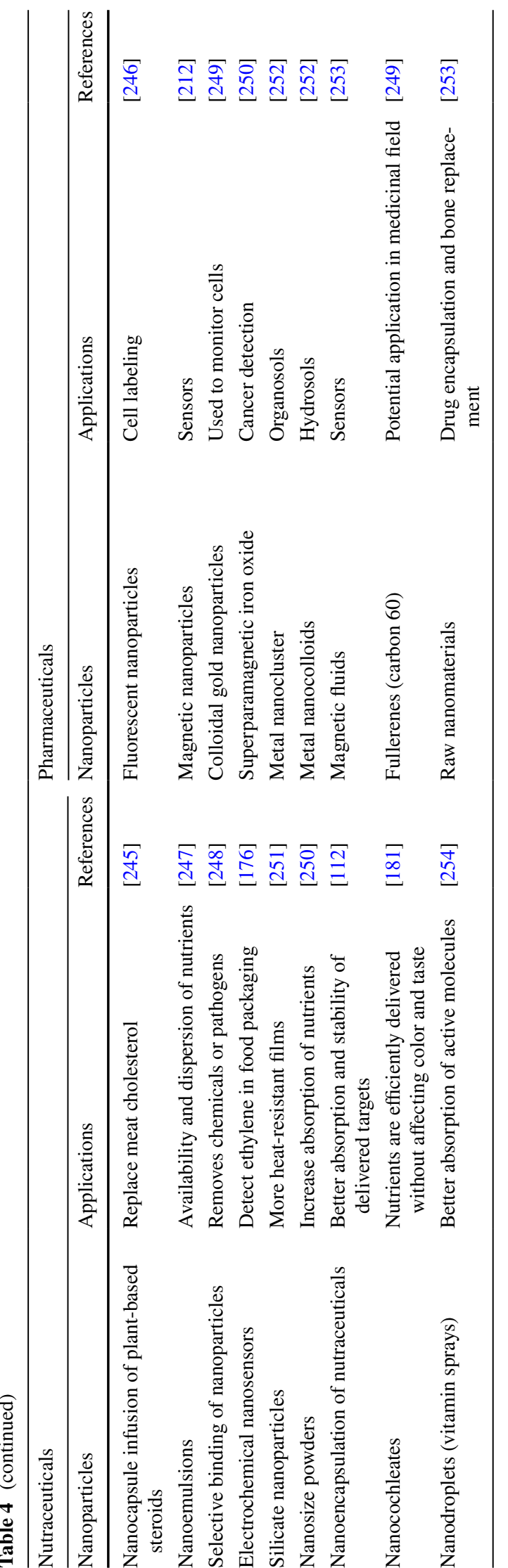

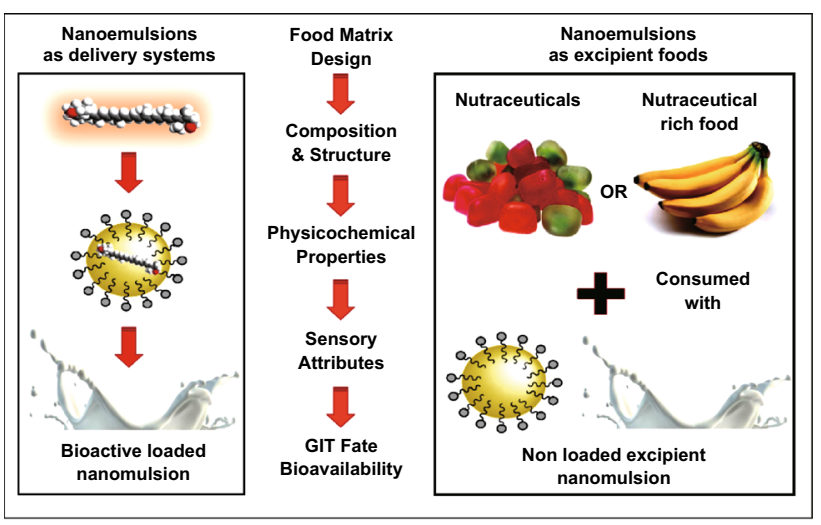

Fig. 7 Schematic diagram showing the delivery of bioactive components in food matrix. This figure was modified and adopted from Ref. [257] with permission

biodistribution [107]. Nanoencapsulation is a process in which the substances are packed in tiny structures, either by nano-structuration, nano-emulsification, or nanocomposites that facilitate controlled release of the core. Different types of nanoencapsulations (nanoparticles, liposomes, nanospheres, micelles, nanocochleates, and nanoemulsions) have been employed depending on the requirement. They can be used as nutritional supplements, to conceal unpleasant taste, improve the bioavailability, and permit efficient dispersion of insoluble supplements without the requirement for surfactants or emulsifiers [99, 108]. The PLA-based nanoparticles were used as a stabilizer in the nanoencapsulated curcumin and quercetin in turmeric extract [16]. Stevioside nanoparticles, nontoxic natural noncaloric sweeteners, were used as antidiabetic nutraceutical agents [109]. The stability and bioavailability of the polyphenols (catechin and epicatechin) in tea were enhanced by encapsulating them in BSA nanoparticles [110]. The nanoformulation of bioactive components which results in their slow release retains the antioxidant potential and enhances the effectiveness of the bioactive molecules. Most of the natural phytochemicals are sensitive to different environments [111]. The entrapment of biologically active components (vitamins, antioxidants, phytochemicals, proteins, lipids and carbohydrates) within the nanoparticles not only gives protection, but also improves function and stability of the bioactive. These nanocapsules when dissolved release the active ingredients like the normal food $[112,113]$. The encapsulation of curcumin in hydrophobically modified 
starch results in increased anticancer activity [114]. Nanocoating can be used as vehicles for functional ingredients during nanoencapsulation, whereas the nanocapsules can be designed to include nanoadditives, antimicrobials, and detoxifying agents (e.g., mycotoxin binding) in the animal feeds. Some of the compounds (e.g., octenyl succinic anhydride- $\varepsilon$-polylysine) are bifunctional molecules which can be either utilized as surfactants or emulsifiers and can be used in the encapsulation of bioactive compounds or drugs or antimicrobials $[115,116]$. Interestingly, nanoencapsulation using lipid molecules increased the antioxidant potential through enhanced solubility and bioavailability and eliminated the undesirable interactions with other food constituents. Nanoliposomes, nanocochleates and archaeosomes are commonly employed lipid-based nanoencapsulation systems. Nanoliposomes are potentially used as cargos for nutrients, enzymes, food antimicrobials, and food additives [117]. Nanoencapsulation of probiotics was also reported previously. The live mixtures of bacterial species supplemented in the food are known as probiotics. The common probiotic foods are cheese, fruitbased drinks, yogurts, and yogurt-type fermented milk and puddings. Encapsulation of these ingredients increases the shelf life of the product. The designer probiotic bacterial species produced using nanoencapsulation technique can be introduced into specific regions of the GI tract where they bind to the specific receptors. These nanoencapsulated designer probiotics may function as de novo vaccines, with the potential to regulate immune responses $[118,119]$.

\subsection{Mixed Nanoparticle Delivery System}

Several studies demonstrated the encapsulation of a bioactive agent using a single type of nanoparticle in the food industry. A mixed nanoparticle delivery system (two or more types of nanoparticles with various functional characteristics) can be more useful for certain applications. It was reported that the encapsulation of chemically sensitive (labile), hydrophobic, biologically active substances using protein nanoparticles followed by mixing with lipid nanoparticles is highly advantageous; protein nanoparticle provides protection to the bioactive; and lipid nanoparticles attribute a source of digestible triglycerides (TGs) that in turn enhances the solubility of the bioactive components in the gastrointestinal tract [96,
120]. The triglycerides get hydrolyzed to free fatty acids and monoglycerides in the small intestine. These hydrolyzed products combine with the bile acids and phospholipids to produce mixed micelles that dissolve the hydrophobic bioactive substances once they are liberated from the encapsulated protein nanoparticles. Few studies have reported the fabrication of either curcumin-loaded or tangeritin-encapsulated zein nanoparticles with antisolvent preparation followed by mixing with lipid NP using microfluidization [121, 122]. They found that enhanced solubilizing ability of the mixed micelle phase significantly improved the bioaccessibility of the hydrophobic bioactive molecules. Nanoparticle clustering is a mixture of positively and negatively charged suspension nanoparticles of proportions resulting in the formation of highly viscous solutions or gels (NP clusters) [123, 124]. The $\mathrm{pH}$ and ionic strength strongly influence the interaction between the oppositely charged particles. This concept is used to produce less calorie food products with enhanced or novel textural features. Trojan Horse NP is the entrapment of nanoparticles in larger particles (hydrogel beads) leading to enhanced functional features. In this delivery method, nanoparticles filled with biologically active substances can be trapped inside the larger particles and are liberated when they reach the site of action [125]. It was utilized to encapsulate nanoemulsions in larger particles (hydrogel beads) where the release depends on the environment [96]. In the upper GI tract, Trojan Horse nanoparticle systems provide protection to oil droplets from lipid digestion and then allow their release within the colon [126]. In addition, digestion rate of lipid droplets in the small intestine and bioaccessibility of encapsulated hydrophobic bioactive substances can be regulated with the Trojan Horse nanoparticle systems [125]. The major achievement of this system is the delivery of the bioactive substances to various regions of the gastrointestinal tract. Nanosized, self-assembled liquid structures are called as fortifying nano-vehicles where the expanded micelles $(<30 \mathrm{~nm})$ are used for the targeted nutraceuticals such as beta-carotene, lycopene, isoflavones, coenzyme $\mathrm{Q}_{10}$ $\left(\mathrm{CoQ}_{10}\right)$, phytosterols, and omega-3 fatty acids [127].

\subsection{Environment-Specific NP-Mediated Delivery}

The development of diagnostic sensors and controlled release delivery systems requires nanoparticles which can alter their characteristics with response to the specific 
environmental stimulations including ionic strength, $\mathrm{pH}$, enzymatic activity, and temperature. Several studies have been carried out to develop NP that can change their properties according to the environment. For instance, bioactive molecules carrying lipid nanoparticles were broken down immediately upon contact with lipase and bioactive molecules were released under simulated GIT conditions [96]. The pancreatic lipase releases the bioactive substances in the small intestine, while the bioactive substance-filled protein nanoparticles were readily broken down in the stomach or small intestine containing proteases. Whey protein-loaded riboflavin, zein nanoparticle-loaded curcumin, and resveratrol are some of the bioactive-loaded protein nanoparticles [96]. In the pharmaceutical industry, $\mathrm{pH}$-sensitive nanoparticles have been used to deliver anticancer molecules to the oncogenic tissues.

\subsection{Natural Carriers}

Nano-vehicles were developed to carry out specific functions. Natural nanocarrier of nutrients such as casein micelle is used for the delivery of hydrophobic, bioactive substances. For hydrophobic nutraceutical delivery in clear acid beverages, $\beta$-lactoglobulin-pectin nanocomplexes and core-shell NP built from heat-aggregated $\beta$-lactoglobulin and nanocoated using beet pectin for bioactive molecules delivery were generated [128, 129]. Milk proteins such as lactoferrin or bovine serum albumin-fused NP were used for the potential drug delivery across the blood-brain barrier, in vivo. Nanoparticles were designed for targeted delivery to specific region, organ, or tissues. For example, targeted delivery to gastric cancer ( $\beta$-casein NP), intestine (BSA NP coated with the fatty acid), and colon (Maillard conjugates of casein and resistant starch) was achieved with these applications [21]. Soy lecithin used to produce aqueous nanodispersions acts as a carrier of hydrophobic bioactive, including fat-soluble vitamins. A sevenfold higher absorption of CoQ in the intestine was observed in the nanodispersion method compared to conventional powder formulations [130]. Colloidosomes are self-connected tiny capsules forming a hollow shell in which bioactive or any other substances can be filled. Beta-carotene encapsulated in nanolipid carriers was designed which permits the hydrophobic $\beta$-carotene to easily disperse and stabilize in beverages [131]. Nanocochleates are nanocolloid particles built mostly from lipids (75\%) that encapsulate the micronutrients and provide stability, protection, and food with improved nutritional values. Starch like nanoparticles significantly improved the stability of the oil-in-water emulsion by preventing lipid oxidation [132].

\section{Nanomaterials in Diagnostic Applications}

Although the conventional molecular diagnostic methods are shown to have higher sensitivity and reproducibility in the detection of pathogens as well as their products (toxins), they are not used in many places due to the requirements for sophistication, high-cost instrumentation, and trained technicians. The unique magnetic, electrical, luminescent, and catalytic activities of nanomaterials are used for the development of rapid, sensitive, and low-cost diagnostic assays for the detection of microbial pathogens. With the application of nanosensors, microbial pathogen detection is rapid, sensitive, accurate, and low labor-intensive. In general, NPs are highly reactive compared to their large-sized particles; hence, it is worth noting to study their possible toxicity in living systems [133, 134].

\subsection{Liposomes}

The detection of bacterial toxins such as botulinum, tetanus, and cholera was achieved with the help of engineered GT1b or GM1 ganglioside-bearing liposomes which are in the range of $\sim 120-130 \mathrm{~nm}$, and they recognize the target toxins. Fluorescent-labeled (rhodamine dye) liposomes were able to detect the lowest concentrations of toxins $(1 \mathrm{nM})$ using fluoroimmunoassay [135].

\subsection{Carbon Nanotubes}

Galactose biofunctionalized single-walled nanotubes (GalSWNTs), used to detect E. coli $\mathrm{O} 157: \mathrm{H} 7$ containing galactose binding surface proteins, revealed a strong aggregation due to their multivalent interactions [136]. It was also reported that application of SWNT-mediated potentiometric aptamer biosensor was used for faster and label-free detection of live bacterial cells; $6 \mathrm{cfu} \mathrm{mL} \mathrm{m}^{-1}$ in milk and $26 \mathrm{cfu} \mathrm{mL}^{-1}$ in apple juice [137]. 


\subsection{Gold Nanoparticles (Au NPs)}

Gold nanoparticles are considered suitable for the adsorption of biomolecules without losing their biological functions, mainly due to their large surface-to-volume ratio and unique physical and chemical properties. Staphylococcus aureus cell membrane protein (protein A) was detected by the AuNP-anti-protein A antibody conjugate immobilized on the immunochromatographic strip. This device functions in a rapid $(<10 \mathrm{~min})$ and highly sensitive $\left(25 \mathrm{ng} \mathrm{mL}^{-1}\right)$ manner for the detection of protein A [138]. The detection of DNA from pathogenic bacteria by utilizing the cationic AuNPs attached to poly (para-phenyleneethynylene) (PPE) provided more rapid and efficient identification than conventional plating and culturing. PPE did not fluoresce in the bound state, whereas the presence of bacteria allowed electrostatic interactions between the bacterial surface and the AuNPs that led to the liberation of PPE from the bound conjugate. Free PPE (fluorescent signals) concentrations can be estimated for the rapid quantification of bacteria [139].

\subsection{Silver Nanoparticles (Ag NPs)}

Application of various antimicrobial substances like metals provides a promising way to control undesirable growth of microorganisms. Basically, the heavy metals have been considered for providing broad-spectrum biocide effects. Among all the metals, the ionic silver considered to have largest antimicrobial activity with long-term biocide properties and low volatility with low toxicity to eukaryotic cells. Furthermore, in recent years, silver has gained popularity because of the spread of antibiotic-resistant Staphylococcus aureus strains, being resistance to silver considered sporadic with a low clinical incidence [140]. The release of silver ions helps to reduce microbial load with sustainable development of various aseptic food containers and antimicrobial surfaces, providing active packaging food systems with promising quality. Very low amount of silver ions (10-100 $\mathrm{mg} \mathrm{Ag} \mathrm{t/kg)} \mathrm{is} \mathrm{required} \mathrm{to} \mathrm{achieve} \mathrm{biocidal}$ effects using in water or low buffered systems. Interestingly, the antimicrobial activity of silver decreases rapidly in the presence of proteins in food system, and hence, the silver amount required was $50-100 \mathrm{mg} \mathrm{Agt} \mathrm{kg}^{-1}$ in realistic food applications [141]. For microbial inhibition activity, using silver ions remains inconsistent in complex food matrix without proper standardization or determination of minimum inhibitory concentration (MIC) value which leads to wrong claims. Also, the overuse of silver as nanoparticles leads to molecular basis of resistance in microorganism, which should be documented properly and considered in technological applications [142].

\section{Toxicological Aspects of Nanomaterials in Food}

The field of nanotechnology is growing, and along with it the public concern regarding the toxicity and environmental impact of nanomaterials is also increasing. Nanoparticlemediated toxicity is stimulated by dynamic, kinetic, and catalytic properties and by functionalization, net particle reactivity, agglomeration, and functional environment [121, 122]. Nanoparticles on the surface of the packaging material are not harmful to human beings, but their translocation and integration into food may affect the human health. The entrance/route, absorption, and distribution of NP in the human body with special attention to their cytotoxicity and genotoxicity were discussed previously [143]. Nanoparticles reach the animal system via skin penetration, ingestion, inhalation, intravenous injections or by the implanted medical apparatus; inside the cells, they interact with the biological macromolecules. Toxicokinetic issues caused by the NP are mainly due to their persistent, non-dissolvable, and nondegradable nature [144]. The lack of consumer awareness, government guidelines, policies, and detection methods for nanotechnology risk assessment warrants better understanding of nanomaterial-based toxicity characterization and regulatory processes. The toxicity increases as the size of the metal-based NP decreases [145]. Nanoparticles are highly reactive substances that can readily cross the membrane barriers and capillaries resulting in different toxicokinetic and toxicodynamic properties. Some NPs bind to proteins and enzymes and result in the stimulation of ROS production and oxidative stress. ROS accumulation causes degeneration of mitochondria and induces apoptosis [146]. Most of the NP-imposed toxicity studies carried out in animals revealed that NP could induce strong toxicity to various organs (liver, kidneys) and immune system. Lack of studies on the impact of NP on human health warrants extensive studies to be carried out. Although silver NP has been used in many commercial nanoproducts, only a few in vivo toxicological studies 
with silver NP have been conducted using the mammalian models (e.g., mice and rats) [147]. Tumor-like changes have been observed in the human cells exposed to $\mathrm{TiO}_{2} \mathrm{NP}$. Different cell lines of the lung, GI tract, and skin were used for the evaluation of nanomaterial-induced toxicity in in vitro conditions [148, 149].

International Conference on Harmonization (ICH) and Organization for Economic Co-operation and Development (OECD) proposed the widely accepted genotoxicity detection methods. These methods were used to determine gene mutations, DNA breaks, Ames test (Salmonella-based mutagenicity assay), and mammalian cell assays including mouse lymphoma gene mutation assay (MLA), comet assay for apoptotic induction, micronucleus (MN) estimation, and in vivo animal experiments [150,151]. Modifications were made in the comet assay by the utilization of bacterial enzymes for the detection of oxidized DNA bases and the quantification of oxidative DNA damage. The significant negative results obtained in the in vivo comet and $\mathrm{MN}$ assay as compared to in vitro comet assay are mainly due to the potential DNA repairing ability of animal models. However, Ames test and the chromosomal aberration tests are not reliable for the detection of nanoproduct related toxicity assessments [152,153]. The in vitro cellular mutagenesis system such as the investigation of epithelial cells from the lungs of the treated animals utilizing bronchoalveolar lavage fluid (BAL), neutrophil level in bronchoalveolar lavage fluid from chronic inflammation, and the correlation between bronchoalveolar lavage fluid-based neutrophil content and the extent of DNA strand damage is determined by in vivo comet assay using lung epithelial cells of the treated animals and hypoxanthin-phosphoribosyltransferase (HPRT) assay. Moreover, in vivo micronucleus and comet assays are considered suitable for the decision-making process by the regulatory authorities [150, 154].

The uptake of exogenous materials, including nanomaterials, induced genetic damages in the cells and animal systems resulting in genotoxicity, which is grouped into primary and secondary genotoxicity. The direct contact between the NP and the genomic DNA without induction of inflammatory reactions is known as primary genotoxicity. This has been reported for some specific nanosilver materials, particulate material of asbestos, and crystalline silica $[150,151]$. The indirect method of primary genotoxicity is via the generation of ROS in the NP-induced target cells or the reduction in intracellular antioxidants. Quartz particles induced primary genotoxicity through ROS generation from mitochondria that causes damage to $\mathrm{DNA}, \mathrm{TiO}_{2}$ and $\mathrm{C}_{60}$ fullerenes induced genotoxicity via the formation of peroxynitrite and $\mathrm{ZnO} \mathrm{NP}$ altered the level of hydroperoxide ions, ROS, malondialdehyde (MDA) concentration, and lactate dehydrogenase activity (LDH) which resulted in DNA fragmentation $[155,156]$. The disruption of membrane integrity, suppression of DNA repair processes, and decreased ATP levels leading to alternative repairing processes in the nucleus are also reported for primary genotoxicity [157]. In secondary genotoxicity, macrophages and neutrophils are activated by the nanomaterials that cause inflammatory reactions along with genetic damage. The ROS and reactive nitrogen species (RNS) and the mediators of phagocytes are responsible for the inflammation-associated DNA damages [151]. The ZnO NP-induced oxidative and nitrative stresses cause elevated inflammatory reactions and genotoxicity in the human monocyte cells. The long-term application of nanoscale granular bio-persistent particles causes chronic inflammation as well as secondary genotoxicity [158]. The physical and chemical parameters potentially affecting ROS generation and genotoxicity induction include particle size, surface, shape, charges, particle dissolution, the ions from nanometals and metal oxides, UV-mediated induction, aggregation, route of interaction with cells, inflammation, and $\mathrm{pH}$ of the medium [159]. Prolonged oxidative stress arising from extreme generation of ROS and obstruction in the regular physiological redox-regulated functions causes detrimental toxic effects at the cellular level which results in DNA damage, uncontrolled cell signaling, altered cell motility, cytotoxicity, apoptosis, and tumor formation [160]. The frequent exposure to NP affects various organs including inflammatory, immune and cardiovascular systems [161].

DNA fragmentation results from DNA single-strand breaks, double-strand breaks, oxidative damage, or chromosomal damage. The tumor suppressor gene $p 53$ is involved in the cellular repairing processes via the initiation of cell cycle arrest, DNA repair, and senescence. Apoptosis and phagocytosis are involved in the degradation of severely damaged cells. The cells not cleared by apoptosis or phagocytosis result in the formation of cancerous cells. Interestingly, microarray and global gene expression-mediated signaling investigations indicated that silver NP-induced genotoxicity through ROS generation, DNA damage, chromosome instability, mitosis suppression, and immune response activation occurs through the JAK-STAT signal transduction pathway 
[162]. The double-strand breaks, and cell cycle arrest initiated by $\mathrm{TiO}_{2} \mathrm{NP}$ stimulated the expression of ataxia telangiectasia-mutated kinase (ATM), p53, CdC-2 followed by the suppression of $H 2 A X$, ATM-and-Rad3-related (ATR), cyclin $B 1$ which proved the genotoxic characteristics of $\mathrm{TiO}_{2} \mathrm{NP}$ [163].

$\mathrm{ZnO}$ NP possesses various unique characteristics like semiconductor property, biocompatibility, pyroelectric, and piezoelectric properties. Due to their antimicrobial nature, they are used in the food industry for food packaging, smart packaging as well as in the nutritional additives. $\mathrm{ZnO}$ NP is less toxic compared to other nanomaterials used in the food industry. However, the potential chromosomal damage, single- and double-strand DNA damages were found in the alloy form of $\mathrm{Cu}-\mathrm{Zn}$ nanoparticles (ANPs) [164, 165]. In plant systems, lower concentrations (10 nM) of 3-mercaptopropanoic acid-CdSe/ZnS quantum dots induced cytotoxicity and genotoxicity. The NP uptake induces the generation of oxidative stresses (ROS, RNS) and lipid peroxidation in the biological systems that play a crucial role in DNA damage, membrane disintegration, and cell death. The bioavailability, fate, behavior, disposition, and toxicity of NP in the environment should be studied in detail to eradicate the problems associated with nanotechnology in food industry [166].

\section{Safety Concerns and Regulatory Laws}

Nanotechnology application in the food industry is tremendous, beginning with ingredients to packaging as well as in the analysis of food products. Apart from their potential uses, their interaction with food system raises a concern about human and animal health. The nanoformulated products are toxic to plants and animals, and no standard regulatory laws regarding their use in food and agri-sector have been introduced so far. Therefore, effective guidelines and policies are required for the safer utilization of nanoparticles in food industry. The regulatory body USFDA is involved in the regulation of nanofoods and food packaging in the USA. Food Standards Australia and New Zealand (FSANZ), a regulatory body under the Food Standards Code actively participates in the regulation of nanofood additives and ingredients in Australia [167, 168]. Risk assessment of nanotechnology in the European Union is performed by the Scientific Committee on Emerging and Newly Identified
Health Risks (SCENIHR). Regulations of the European Union emphasized that the nanotechnology-based food ingredients should undergo safety assessment before being authorized for human use [169]. The nanofood or food ingredients are completely covered by the European Union Novel Foods Regulation (EC 258-97). The re-evaluation program by European Food Safety Authority (EFSA) suggested that the authorized nanoadditives before 2009 and food packaging materials should be treated as per the reevaluation program. While Japan and China are the major nanomaterial producing countries, they do not have proper nanotechnology-specific regulations [170]. The lack of food regulations in several countries is due to less information regarding exposure, availability, and toxicity to human. Due to the emerging regulatory problems, several countries have demanded a regulatory system for handling risks associated with the nanofood. Complete government guidelines and legislations, as well as rigorous toxicological screening methodologies are essential for the legal nanotechnological applications. A widely accepted international regulatory system is urgently required for the regulation of the utilization of nanoparticles in food industry [171, 172].

\section{Conclusion and Future Perspective}

Nanotechnology plays a major role in the food sector through the quality food production ends with advanced processing, packaging, and long-term storage, provided enormous growth in food industry through enhancement in food quality by improving its flavor and texture. The nanomaterials and nanosensors help the consumers providing information on the state of the food inside and its nutritional status with enhanced security through pathogen detection. Most of the food bioactives against various diseases are hydrophobic in nature having least bioavailability and stability; thus, the nanotechnology-based delivery systems provided an enhanced bioavailability and targeted delivery of food bioactive compounds. The nanotechnology-based foods give significant challenges to both government and industry, ensuring the consumer confidence and acceptance for nanofoods available in market. Active utilization of nanocolloidal particles in different branches of food industry, such as food quality, safety, nutrition, processing, and packaging, has been widely reported recently. The properties and behavior 
of colloidal particles are important to design foods which are safer and healthier with improved quality and sustainability.

Nanoparticles are manufactured all over the world, though very few countries possess the standard regulatory rules for the utilization of nanotechnology in food products. Insufficient scientific exploration on nanosystems creates difficulties in arriving at any conclusions regarding their efficacy. The applications of nanoparticles in food packaging are less harmful than the utilization of nanoparticles as a food ingredient. There is always a threat that nanomaterials may enter the food chain through the air, water, and soil during their manufacture and usage leading to DNA damage, cell membrane disruption, and cell death. So far, very few in vivo studies have been conducted on the effects of nanofoods in human and animal health. There should be appropriate labeling and regulations advised for marketing of nanofoods which can help to increase consumer acceptability. Thus, utilization of these nanotechnologies, if managed and regulated correctly, can play a significant role in improving food processing and product quality which will benefited for human health and well-being.

Acknowledgements This work was funded by National Key R\&D Program of China (2018YFC1706200), National Natural Science Fund of China (31571735, 81522049), Shanghai Science and Technology Committee Project (17JC1404300), Zhejiang Provincial Ten Thousands Program for Leading Talents of Science and Technology Innovation (2018R52050), Zhejiang Provincial Program for the Cultivation of High-level Innovative Health talents, TCM Foundation for Distinguished Young Talents of Zhejiang Province (2020ZQ014), Talent Project of Zhejiang Chinese Medical University (2019ZR15), and Opening project of Zhejiang provincial preponderant and characteristic subject of Key University (Traditional Chinese Pharmacology), Zhejiang Chinese Medical University (ZYAOX2018004,ZYAOX2018019).

Open Access This article is licensed under a Creative Commons Attribution 4.0 International License, which permits use, sharing, adaptation, distribution and reproduction in any medium or format, as long as you give appropriate credit to the original author(s) and the source, provide a link to the Creative Commons licence, and indicate if changes were made. The images or other third party material in this article are included in the article's Creative Commons licence, unless indicated otherwise in a credit line to the material. If material is not included in the article's Creative Commons licence and your intended use is not permitted by statutory regulation or exceeds the permitted use, you will need to obtain permission directly from the copyright holder. To view a copy of this licence, visit http://creativecommons.org/licenses/by/4.0/.

\section{References}

1. T.V. Duncan, Applications of nanotechnology in food packaging and food safety: barrier materials, antimicrobials and sensors. Curr. Opin. Colloid Interface Sci. 363, 1-24 (2011). https://doi.org/10.1016/J.JCIS.2011.07.017

2. C. Parisi, M. Vigani, E. Rodríguez-Cerezo, Agricultural nanotechnologies: what are the current possibilities? Nano Today 10, 124-127 (2015). https://doi.org/10.1016/J.NANTO D.2014.09.009

3. Y.S. El-Temsah, E.J. Joner Bioforsk, Impact of $\mathrm{Fe}$ and $\mathrm{Ag}$ nanoparticles on seed germination and differences in bioavailability during exposure in aqueous suspension and soil. Environ. Toxicol. 165, 16 (2006). https://doi.org/10.1002/ tox. 20610

4. M. Kumari, A. Mukherjee, N. Chandrasekaran, Genotoxicity of silver nanoparticles in Allium cepa. Sci. Total Environ. 407, 5243-5246 (2009). https://doi.org/10.1016/J. SCITOTENV.2009.06.024

5. R. Nair, S.H. Varghese, B.G. Nair, T. Maekawa, Y. Yoshida, D.S. Kumar, Nanoparticulate material delivery to plants. Plant Sci. 179, 154-163 (2010). https://doi.org/10.1016/J. PLANTSCI.2010.04.012

6. T.V. Duncan, The communication challenges presented by nanofoods. Nat. Nanotechnol. 6, 683-688 (2011). https:// doi.org/10.1038/nnano.2011.193

7. A.C. Tricco, H.M. Ashoor, J. Antony, Z. Bouck, M. Rodrigues et al., Essential Medicines List (EML) 2019 Application for the inclusion of long acting insulin analogues including biosimilar in the WHO Model List of Essential Medicines, as treatments used for patients with diabetes type 1 (2019)

8. W.H. Sperber, M.P. Doyle, Introduction to the Microbiological spoilage of foods and beverages, in Compendium of the microbiological spoilage of foods and beverages (Springer International Publishing, New Yark, 2009). pp. 1-40

9. B.S. Sekhon, Food nanotechnology-an overview. Nanotechnol. Sci. Appl. 3, 1-15 (2010). https://doi.org/10.2147/ NSA.S8677

10. V.K. Bajpai, M. Kamle, S. Shukla, D.K. Mahato, P. Chandra et al., Prospects of using nanotechnology for food preservation, safety, and security. J. Food Drug Anal. 26, 12011214 (2018). https://doi.org/10.1016/J.JFDA.2018.06.011

11. S. Kang, M. Pinault, L.D. Pfefferle, M. Elimelech, M. Engineering, Single-walled carbon nanotubes exhibit strong antimicrobial activity. Langmuir 23, 8670-8673 (2007). https://doi.org/10.1021/la701067r

12. K.W. Powers, S.C. Brown, V.B. Krishna, S.C. Wasdo, B.M. Moudgil, S.M. Roberts, Research strategies for safety evaluation of nanomaterials. Part VI. Characterization of nanoscale particles for toxicological evaluation. Toxicol. Sci. 90, 296-303 (2006). https://doi.org/10.1093/toxsci/ kfj099 
13. H.M.C. Azeredo, C.L.M. Henrique, D. Wood, T.G. Williams, J.A.-B. Roberto, H.M. Tara, Nanocomposite edible films from mango puree reinforced with cellulose nanofibers. J. Food Sci. 74, 31-35 (2009). https://doi.org/10.111 1/j.1750-3841.2009.01186.x

14. S. Naoto, O. Hiroshi, N. Mitsutoshi, Mitsutoshi, micro- and nanotechnology for food processing. (Food safety series) resource: engineering and technology for a sustainable. World. Am. Soc. Agric. Eng. 16, 19 (2009)

15. EFSA Scientific Committee, The potential risks arising from nanoscience and nanotechnologies on food and feed safety. Sci Opin Sci Comm (2009). https://doi.org/10.2903/j. efsa.2009.958

16. S.K. Yadav, Tissue science \& engineering realizing the potential of nanotechnology for agriculture and food technology. J. Tissue Sci. Eng. 8, 8-11 (2017). https://doi. org/10.4172/2157-7552.1000195

17. B.K. Gilligan, Nanny, Nano, Boo, Boo Food ? (2008). http://www.towerofbabel.com/blog/2008/08/28/nanny -nano-boo-boo-food/

18. M.F.F. Pocas, T.F. Delgado, F.A.R. Oliveira, Smart packaging technologies for fruits and vegetables. in Smart Packaging Technologies for Fast Moving Consumer Goods, ed. by J. Kerry, P. Butler (2008). https://doi.org/10.1002/97804 70753699.ch9

19. A.L. Brody, B. Bugusu, J.H. Han, C.K. Sand, T.H. Mchugh, Innovative food packaging solutions. J. Food Sci. 73, 107-116 (2008). https://doi.org/10.111 1/j.1750-3841.2008.00933.x

20. J.P. Kerry, M.N. O'Grady, S.A. Hogan, Past, current and potential utilisation of active and intelligent packaging systems for meat and muscle-based products: a review. Meat Sci. 74, 113-130 (2006). https://doi.org/10.1016/J.MEATS CI.2006.04.024

21. X. He, H. Deng, H. Hwang, The current application of nanotechnology in food and agriculture. J. Food Drug Anal. 27, 1-21 (2019). https://doi.org/10.1016/J. JFDA.2018.12.002

22. A. Sorrentino, G. Gorrasi, V. Vittoria, Potential perspectives of bio-nanocomposites for food packaging applications. Trends Food Sci. Technol. 18, 84-95 (2007). https:// doi.org/10.1016/J.TIFS.2006.09.004

23. D.S. Cha, M.S. Chinnan, Biopolymer-based antimicrobial packaging: a review. Crit. Rev. Food Sci. Nutr. 44, 223-237 (2004). https://doi.org/10.1080/10408690490464276

24. J. Weiss, P. Takhistov, D.J. Mcclements, Functional materials in food nanotechnology. J. Food Sci. 71, 107-116 (2006). https://doi.org/10.1111/j.1750-3841.2006.00195.x

25. R.J.B. Pinto, S. Daina, P. Sadocco, C.P. Neto, T. Trindade, Antibacterial activity of nanocomposites of copper and cellulose. Biomed. Res. Int. 2013, 280512 (2013). https://doi. org/10.1155/2013/280512

26. S.D.F. Mihindukulasuriya, L.-T. Lim, Nanotechnology development in food packaging: a review. Trends Food Sci. Technol. 40, 149-167 (2014). https://doi.org/10.1016/J. TIFS.2014.09.009
27. A. Brody, Nano and food packaging technologies converge. Food Technol. 60, 92-94 (2006)

28. Y. Inoue, M. Hoshino, H. Takahashi, T. Noguchi, T. Murata, Y. Kanzaki, H. Hamashima, M. Sasatsu, Bactericidal activity of $\mathrm{Ag}$-zeolite mediated by reactive oxygen species under aerated conditions. J. Inorg. Biochem. 92, 37-42 (2002). https://doi.org/10.1016/S0162-0134(02)00489-0

29. Y. Matsumura, K. Yoshikata, S. Kunisaki, T. Tsuchido, Mode of bactericidal action of silver zeolite and its comparison with that of silver nitrate. Appl. Environ. Microbiol. 69, 4278-4281 (2003). https://doi.org/10.1128/ AEM.69.7.4278

30. S. Egger, R.P. Lehmann, M.J. Height, M.J. Loessner, M. Schuppler, Antimicrobial properties of a novel silver-silica nanocomposite materials. Appl. Environ. Microbiol. 75, 2973-2976 (2009). https://doi.org/10.1128/AEM.01658-08

31. N. Sinha, J. Ma, J.T.W. Yeow, Carbon nanotube-based sensors. J. Nanosci. Nanotechnol. 6, 573-590 (2006). https:// doi.org/10.1166/jnn.2006.121

32. Nanotechnology Can Enhance Food Packaging (2010). http:// www.plastemart.com/plastic-technical-articles/Amorphouspolymers-can-produce-transparent-clear-products-/1260

33. J. Rhim, P.K.W. Ng, J. Rhim, Natural biopolymer-based nanocomposite films for packaging. Crit. Rev. Food Sci. Nutr. 47, 411-433 (2007). https://doi.org/10.1080/104083906008463 66

34. J.M. Lagaron, L. Cabedo, D. Cava, J.L. Feijoo, R. Gavara, E. Gimenez, Improving packaged food quality and safety. Part 2 : Nanocomposites. Food Addit. Contam. 22, 994-998 (2005). https://doi.org/10.1080/02652030500239656

35. Q. Chaudhry, M. Scotter, J. Blackburn, B. Ross, L. Castle, R. Aitken, R. Watkins, Applications and implications of nanotechnologies for the food sector. Food Addit. Contam. 25, 241-258 (2008). https://doi.org/10.1080/026520307017445 38

36. S. Ray, S.Y. Quek, A. Easteal, X.D. Chen, The potential use of polymer-clay nanocomposites in food packaging. Int. J. Food Eng. 2, 1-11 (2006). https://doi.org/10.2202/1556-3758.1149

37. J.W. Rhim, H.M. Park, C.S. Ha, Bio-nanocomposites for food packaging applications. Prog. Polym. Sci. 38, 16291652 (2013). https://doi.org/10.1016/J.PROGPOLYMS CI.2013.05.008

38. F.L. Yang, X.G. Li, F. Zhu, C.L. Lei, Structural characterization of nanoparticles loaded with garlic essential oil and their insecticidal activity against Tribolium castaneum (Herbst) (Coleoptera: Tenebrionidae). J. Agric. Food Chem. 57, 10156-10162 (2009). https://doi.org/10.1021/jf9023118

39. F.E.S. An, A.G. Onzalez, Y.U.A.N.Y. Ao, Phytoglycogen octenyl succinate, an amphiphilic carbohydrate nanoparticle, and $\varepsilon$-polylysine to improve lipid oxidative stability of emulsions. J. Agric. Food Chem. 58, 660-667 (2010). https ://doi.org/10.1021/jf903170b

40. S. Neethirajan, D.S. Jayas, Nanotechnology for the food and bioprocessing industries. Food Bioprocess Technol. 4, 39-47 (2015). https://doi.org/10.1007/s11947-010-0328-2 
41. A. Garland, Nanotechnology in Plastics Packaging: Commercial Applications in Nanotechnology (Pira International Limited, London, 2004), pp. 14-63

42. M.V. Dias, N.F.F. de Soares, S.V. Borges, M.M. de Sousa, C.A. Nunes, I.R.N. de Oliveira, E.A.A. Medeiros, Use of allyl isothiocyanate and carbon nanotubes in an antimicrobial film to package shredded, cooked chicken meat. Food Chem. 141, 3160-3166 (2013). https://doi.org/10.1016/j. foodchem.2013.05.148

43. M.A. Morris, S.C. Padmanabhan, M.C. Cruz-Romero, E. Cummins, Development of active, nanoparticle, antimicrobial technologies for muscle-based packaging applications. Meat Sci. 132, 163-178 (2017). https://doi.org/10.1016/J.MEATS CI.2017.04.234

44. R. Drew, T. Hagen, Nanotechnologies in food packaging: an exploratory appraisal of safety and regulation. Food Standards Australia New Zealand 75, 1 (2016)

45. Z. Li, C. Sheng, Nanosensors for food safety. J. Nanosci. Nanotechnol. 14, 905-912 (2014). https://doi.org/10.1166/ jnn.2014.8743

46. M.M. Berekaa, Review article nanotechnology in food industry; advances in food processing, packaging and food safety. Int. J. Curr. Microbiol. App. Sci. 4, 345-357 (2015)

47. M.A. Augustin, P. Sanguansri, Chapter 5: nanostructured materials in the food industry. Adv. Food Nutr. Res. 58, 183213 (2009). https://doi.org/10.1016/s1043-4526(09)58005-9

48. D. Branton, D.W. Deamer, A. Marziali, H. Bayley, S.A. Benner et al., The potential and challenges of nanopore sequencing. Nat. Biotechnol. 26, 1146-1153 (2009). https://doi. org/10.1038/nbt.1495

49. C. Maneerat, Y. Hayata, Antifungal activity of $\mathrm{TiO}_{2}$ photocatalysis against Penicillium expansum in vitro and in fruit tests. Int. J. Food Microbiol. 107, 99-103 (2006). https://doi. org/10.1016/J.IJFOODMICRO.2005.08.018

50. T. King, M.J. Osmond-McLeod, L.L. Duffy, Nanotechnology in the food sector and potential applications for the poultry industry. Trends Food Sci. Technol. 72, 62-73 (2018). https ://doi.org/10.1016/J.TIFS.2017.11.015

51. A. Ditta, How helpful is nanotechnology in agriculture? Adv. Nat. Sci: Nanosci. Nanotechnol. 3, 033002 (2012). https://doi. org/10.1088/2043-6262/3/3/033002

52. M. Ghasemi-Varnamkhasti, C. Apetrei, J. Lozano, A. Anyogu, Potential use of electronic noses, electronic tongues and biosensors as multisensor systems for spoilage examination in foods. Trends Food Sci. Technol. 80, 71-92 (2018). https:// doi.org/10.1016/J.TIFS.2018.07.018

53. N. Dasgupta, S. Ranjan, D. Mundekkad, C. Ramalingam, R. Shanker, A. Kumar, Nanotechnology in agro-food: from field to plate. Food Res. Int. 69, 381-400 (2015). https://doi. org/10.1016/J.FOODRES.2015.01.005

54. A. Emblem, H. Emblem, Packaging Technology: Fundamentals, Materials and Processes (Woodhead Publishing Ltd., Cambridge, 2012), pp. 287-309

55. A.V. Fedotova, A.G. Snezhko, O.A. Sdobnikova, L.G. Samoilova, T.A. Smurova, A.A. Revina, E.B. Khailova,
Packaging materials manufactured from natural polymers modified with silver nanoparticles. Plast. Massy 7, 42-47 (2009)

56. L. Angiolillo, A. Conte, M.A. Del Nobile, Packaging and Shelf Life of Produce, Reference Module in Food Science (Elsevier, Dordrecht, 2016). https://doi.org/10.1016/B978-008-100596-5.03220-0

57. G. Pyrgiotakis, A. Vasanthakumar, Y. Gao, M. Eleftheriadou, E. Toledo et al., Inactivation of foodborne microorganisms using engineered water nanostructures (EWNS). Environ. Sci. Technol. 49, 3737-3745 (2015). https://doi.org/10.1021/ es505868a

58. P. Šimon, Q. Chaudhry, D. Bakoš, Migration of engineered nanoparticles from polymer packaging to food-a physicochemical view. J. Food Nutr. Res. 47, 105-113 (2008)

59. C. Damm, H. Münstedt, A. Rösch, Long-term antimicrobial polyamide 6/silver-nanocomposites. J. Mater. Sci. 42, 60676073 (2007). https://doi.org/10.1007/s10853-006-1158-5

60. S. Azlin-Hasim, M.C. Cruz-Romero, E. Cummins, J.P. Kerry, M.A. Morris, The potential use of a layer-by-layer strategy to develop LDPE antimicrobial films coated with silver nanoparticles for packaging applications. Curr. Opin. Colloid Interface Sci. 461, 239-248 (2016). https://doi. org/10.1016/J.JCIS.2015.09.021

61. R.T. De Silva, P. Pasbakhsh, S.M. Lee, A.Y. Kit, ZnO deposited/encapsulated halloysite-poly (lactic acid) (PLA) nanocomposites for high performance packaging films with improved mechanical and antimicrobial properties. Appl. Clay Sci. 111, 10-20 (2015). https://doi.org/10.1016/J. CLAY.2015.03.024

62. E. Taghinezhad, A. Ebadollahi, Potential application of chitosan-clay coating on some quality properties of lemon during storage. AgricEngInt: CIGR J. 19, 189-194 (2017)

63. H.H. Khalaf, A.M. Sharoba, H.H. El-Tanahi, M.K. Morsy, Stability of antimicrobial activity of pullulan edible films incorporated with nanoparticles and essential oils and their impact on turkey. J. Food Dairy Sci. Mansoura Univ. 4, 557-573 (2013)

64. M. Cushen, J. Kerry, M. Morris, M. Cruz-Romero, E. Cummins, Migration and exposure assessment of silver from a PVC nanocomposite. Food Chem. 139, 389-397 (2013). https://doi.org/10.1016/J.FOODCHEM.2013.01.045

65. S. Djokic, Synthesis and antimicrobial activity of silver citrate complexes. Bioinorg. Chem. Appl. 2008, 436458 (2008). https://doi.org/10.1155/2008/436458

66. M. Zarei, A. Jamnejad, E. Khajehali, Antibacterial effect of silver nanoparticles against four foodborne pathogens. Jundishapur J. Microbiol. 7, 1-4 (2014). https://doi. org/10.5812/jjm.8720

67. M.E. Vance, T. Kuiken, E.P. Vejerano, S.P. Mcginnis, M.F.H. Jr, D. Rejeski, M.S. Hull, Nanotechnology in the real world: redeveloping the nanomaterial consumer products inventory. Beilstein J. Nanotechnol. 6, 1769-1780 (2015). https://doi.org/10.3762/bjnano.6.181

68. M.C. Siqueira, G.F. Coelho, M.R. De Moura, J.D. Bresolin, S.Z. Hubinger, J.M. Marconcini, L.H.C. Mattoso, 
Evaluation of antimicrobial activity of silver nanoparticles for carboxymethylcellulose film applications in food packaging. J. Nanosci. Nanotechnol. 14, 5512-5517 (2014). https://doi.org/10.1166/jnn.2014.8991

69. S.T. Khan, A.A. Al-Khedhairy, J.J. Musarrat, $\mathrm{ZnO}$ and $\mathrm{TiO}_{2}$ nanoparticles as novel antimicrobial agents for oral hygiene: a review. Nanopart. Res. 17, 276-292 (2015). https://doi.org/10.1007/s11051-015-3074-6

70. S.M. Rodrigues, P. Demokritou, N. Dokoozlian, C.O. Hendren, D.B. Karn et al., Environmental science nanotechnology for sustainable food production: promising opportunities and scientific challenges. Environ. Sci. Nano 1, 767-781 (2017). https://doi.org/10.1039/c6en00573j

71. V. Krishna, S. Pumprueg, S.H. Lee, J. Zhao, W. Sigmund, B. Koopman, B.M. Moudgil, Photocatalytic disinfection with titanium dioxide coated multi-wall carbon nanotubes. Process Saf. Environ. Prot. 83, 393-397 (2005). https://doi. org/10.1205/PSEP.04387

72. A. Vohra, D.Y. Goswami, D.A. Deshpande, S.S. Block, Enhanced photocatalytic inactivation of bacterial spores on surfaces in air. J. Ind. Microbiol. Biotechnol. 32, 364-370 (2005). https://doi.org/10.1007/s10295-005-0006-y

73. K.H. Cho, J.E. Park, T. Osaka, S.G. Park, The study of antimicrobial activity and preservative effects of nanosilver ingredient. Electrochim. Acta 51, 956-960 (2005). https:// doi.org/10.1016/J.ELECTACTA.2005.04.071

74. B. Kim, D. Kim, D. Cho, S. Cho, Bactericidal effect of $\mathrm{TiO}_{2}$ photocatalyst on selected food-borne pathogenic bacteria. Chemosphere 52, 277-281 (2003). https://doi.org/10.1016/ S0045-6535(03)00051-1

75. M.L. Cerrada, C. Serrano, M. Sanchez-Chaves, M. Fernandez-Garcıa, F. Fernandez-Martın et al., Self-sterilized EVOH-TiO2 nanocomposites: interface effects on biocidal properties. Adv. Funct. Mater. 18, 1949-1960 (2008). https ://doi.org/10.1002/adfm.200701068

76. M. Rai, P.S. Jogee, A.P. Ingle, Emerging nanotechnology for detection of mycotoxins in food and feed. Int. J. Food Sci. Nutr. 66, 363-370 (2015). https://doi.org/10.3109/09637 486.2015.1034251

77. J. Schmitt, S. Hajiw, A. Lecchi, J. Degrouard, A. Salonen, M. Impéror-Clerc, B. Pansu, Formation of superlattices of gold nanoparticles using ostwald ripening in emulsions: transition from fcc to bcc structure. J. Phys. Chem. B 120, 5759-5766 (2016). https://doi.org/10.1021/acs.jpcb.6b03287

78. B. Duncan, X. Li, R.F. Landis, S.T. Kim, A. Gupta et al., Nanoparticle-stabilized capsules for the treatment of bacterial biofilms. ACS Nano 9, 7775-7782 (2015). https://doi. org/10.1021/acsnano.5b01696

79. H.C.B. Paula, E.F. Oliveira, M.J.M. Carneiro, R.C.M. de Paula, Matrix effect on the spray drying nanoencapsulation of lippia sidoides essential oil in chitosan-native gum blends. Planta Med. 83, 392-397 (2017). https://doi. org/10.1055/s-0042-107470

80. A.S. Gaspar, F.E. Wagner, V.S. Amaral, S.A. Costa Lima, V.A. Khomchenko, J.G. Santos, B.F.O. Costa, L. Durães, Development of a biocompatible magnetic nanofluid by incorporating SPIONs in Amazonian oils. Spectrochim. Acta A: Mol. Biomol. Spectrosc. 172, 135-146 (2017). https://doi. org/10.1016/j.saa.2016.04.022

81. S.F. Hosseini, M. Zandi, M. Rezaei, F. Farahmandghavi, Two-step method for encapsulation of oregano essential oil in chitosan nanoparticles: preparation, characterization and in vitro release study. Carbohydr. Polym. 95, 50-56 (2013). https://doi.org/10.1016/J.CARBPOL.2013.02.031

82. K. Li, S. Yin, X. Yang, C. Tang, Z. Wei, Fabrication and characterization of novel antimicrobial films derived from thymol-loaded zein-sodium caseinate (SC) nanoparticles. J. Agric. Food Chem. 60, 11592-11600 (2012). https://doi. org/10.1021/jf302752v

83. C. Gomes, R.G. Moreira, E. Castell-perez, Poly (DL-lactideco-glycolide) (PLGA) nanoparticles with entrapped trans-cinnamaldehyde and eugenol for antimicrobial delivery applications. J. Food Sci. 76, 16-24 (2011). https://doi.org/10.111 $1 / \mathrm{j} .1750-3841.2010 .01985 . x$

84. O. Gortzi, S. Lala, I. Chinou, J. Tsaknis, Evaluation of the antimicrobial and antioxidant activities of Origanum dictamnus extracts before and after encapsulation in liposomes. Molecules 12, 932-945 (2007). https://doi.org/10.3390/12050932

85. D. Valenti, A. De Logu, G. Loy, L. Bonsignore, F. Cottiglia, A.M. Fadda, Liposome-incorporated Santolina insularis essential oil: preparation, characterization and in vitro antiviral activity. J. Liposome Res. 11, 73-90 (2001). https://doi. org/10.1081/LPR-100103171

86. Y. Wu, Y. Luo, Q. Wang, Antioxidant and antimicrobial properties of essential oils encapsulated in zein nanoparticles prepared by liquid-liquid dispersion method. LWT - Food Sci. Technol. 48, 283-290 (2012). https://doi.org/10.1016/J. LWT.2012.03.027

87. A.R. Bilia, C. Guccione, B. Isacchi, C. Righeschi, F. Firenzuoli, M.C. Bergonzi, Essential oils loaded in nanosystems: a developing strategy for a successful therapeutic approach. Evid-Based Compl. Alt. Med. 2014, 651593 (2014). https:// doi.org/10.1155/2014/651593

88. F.O.M.S. Abreu, E.F. Oliveira, H.C.B. Paula, R.C.M. de Paula, Chitosan/cashew gum nanogels for essential oil encapsulation. Carbohydr. Polym. 89, 1277-1282 (2012). https:// doi.org/10.1016/J.CARBPOL.2012.04.048

89. Y. Zhang, Y. Niu, Y. Luo, M. Ge, T. Yang, L. Yu, Q. Wang, Fabrication, characterization and antimicrobial activities of thymol-loaded zein nanoparticles stabilized by sodium caseinate-chitosan hydrochloride double layers. Food Chem. 142, 269-275 (2014). https://doi.org/10.1016/j.foodc hem.2013.07.058

90. A. Iannitelli, R. Grande, A. di Stefano, M. di Giulio, P. Sozio et al., Potential antibacterial activity of carvacrol-loaded poly(DL-lactide-co-glycolide) (PLGA) nanoparticles against microbial biofilm. Int. J. Mole. Sci. 12, 5039-5051 (2011). https://doi.org/10.3390/ijms12085039

91. H. Gu, P.L. Ho, E. Tong, L. Wang, B. Xu, Presenting vancomycin on nanoparticles to enhance antimicrobial activities. Nano Lett. 3, 1261-1263 (2003). https://doi.org/10.1021/ nl034396z 
92. L. Bi, L. Yang, G. Narsimhan, A.K. Bhunia, Y. Yao, Designing carbohydrate nanoparticles for prolonged efficacy of antimicrobial peptide. J. Controlled Release 150, 150-156 (2011). https://doi.org/10.1016/J.JCONREL.2010.11.024

93. M.K. Morsy, H.H. Khalaf, A.M. Sharoba, H.H. El-tanahi, C.N. Cutter, Incorporation of essential oils and nanoparticles in pullulan films to control foodborne pathogens on meat and poultry products. J. Food Sci. 79, 675-684 (2014). https://doi. org/10.1111/1750-3841.12400

94. P. Wen, D.H. Zhu, K. Feng, F.-J. Liu, W.Y. Lou, N. Li, M.-H. Zong, H. Wu, Fabrication of electrospun polylactic acid nanofilm incorporating cinnamon essential oil/ $\beta$-cyclodextrin inclusion complex for antimicrobial packaging. Food Chem. 196, 996-1004 (2016). https://doi.org/10.1016/J.FOODC HEM.2015.10.043

95. M.N.V.R. Kumar, Nano and microparticles as controlled drug delivery devices. J. Pharm. Pharmaceut. 3, 234-258 (2000)

96. D.J. McClements, The future of food colloids: next-generation nanoparticle delivery systems. Curr. Opin. Colloid Interface Sci. 28, 7-14 (2017). https://doi.org/10.1016/J. COCIS.2016.12.002

97. R. Zhang, D.J. McClements, Enhancing nutraceutical bioavailability by controlling the composition and structure of gastrointestinal contents: emulsion-based delivery and excipient systems. Food Struct. Neth 10, 21-36 (2016). https://doi.org/10.1016/J.FOOSTR.2016.07.006

98. Q.B. Hildeliza, J. Chanona-pe, L.S.M. Jose, G.F. Gutie, A. Jimene, Nanoencapsulation: a new trend in food engineering processing. Food Eng. Rev. 2, 39-50 (2010). https://doi. org/10.1007/s12393-009-9012-6

99. M. Cushen, J. Kerry, M. Morris, M. Cruz-Romero, E. Cummins, Nanotechnologies in the food industry-recent developments, risks and regulation. Trends Food Sci. Technol. 24, 30-46 (2012). https://doi.org/10.1016/J. TIFS.2011.10.006

100. D.J. Mcclements, Edible nanoemulsions: fabrication, properties, and functional performance. Soft Matter 7, 22972316 (2011). https://doi.org/10.1039/c0sm00549e

101. I.J. Joye, G. Davidov-Pardo, D.J. McClements, Nanotechnology for increased micronutrient bioavailability. Trends Food Sci. Technol. 40, 168-182 (2014). https://doi. org/10.1016/J.TIFS.2014.08.006

102. D.J. Mcclements, H. Xiao, Excipient foods: designing food matrices that improve the oral bioavailability of pharmaceuticals and nutraceuticals. Food Funct. 5, 1307-1632 (2014). https://doi.org/10.1039/c4fo00100a

103. D.J. Mcclements, J. Rao, Food-grade nanoemulsions: formulation, fabrication, properties, performance, biological fate, and potential toxicity. Crit. Rev. Food Sci. Nutr. 51, 285-330 (2011). https://doi.org/10.1080/10408 398.2011 .559558

104. L. Salvia-Trujillo, C. Qian, O. Martín-Belloso, D.J. McClements, Influence of particle size on lipid digestion and $\beta$-carotene bioaccessibility in emulsions and nanoemulsions. Food Chem. 141, 1472-1480 (2013). https://doi. org/10.1016/J.FOODCHEM.2013.03.050
105. B. Bigliardi, F. Galati, Innovation trends in the food industry: the case of functional foods. Trends Food Sci. Technol. 31, 118-129 (2013). https://doi.org/10.1016/J.TIFS.2013.03.006

106. X. Wang, Y. Jiang, Y.W. Wang, M.T. Huang, C.T. Ho, Q. Huang, Enhancing anti-inflammation activity of curcumin through O/W nanoemulsions. Food Chem. 108, 419-424 (2008). https://doi.org/10.1016/J.FOODCHEM.2007.10.086

107. A. Kumari, V. Kumar, S.K. Yadav, Nanotechnology: a tool to enhance therapeutic values of natural plant products. Trends Med. Res. 7, 34-42 (2012). https://doi.org/10.3923/ tmr.2012.34.42

108. N. Dura, P.D. Marcato, Review Nanobiotechnology perspectives. Role of nanotechnology in the food industry: A review. Int. J. Food Sci. Technol. 48, 1127-1134 (2013). https://doi. org/10.1111/ijfs.12027

109. S.C. Yadav, S.K. Yadav, A. Sood, M. Sharma, B. Singh, Development of antidiabetic nanomedicine from stevioside. J. Biomed. Nanotechnol. 7, 54-55 (2011). https://doi. org/10.1166/jbn.2011.1198

110. R. Yadav, D. Kumar, A. Kumari, S.K. Yadav, Encapsulation of catechin and epicatechin on bsa nps improved their stability and antioxidant potential. Excli J. 13, 331-346 (2014)

111. I.A. Siddiqui, Hasan Mukhtar, Nanochemoprevention by bioactive food components: a perspective. Pharm. Res. 27, 1054 1060 (2010). https://doi.org/10.1007/s11095-010-0087-9

112. S. Wang, R. Su, S. Nie, M. Sun, J. Zhang, D. Wu, N. Moustaid-Moussa, Application of nanotechnology in improving bioavailability and bioactivity of diet-derived phytochemicals. J. Nutr. Biochem. 25, 363-376 (2014). https:// doi.org/10.1016/J.JNUTBIO.2013.10.002

113. H. Chen, J. Weiss, F. Shahidi, Nanotechnology in nutraceuticals and functional foods. Food Technol. 60(3), 30-36 (2006). https://doi.org/10.1201/9781315370859-14

114. H. Yu, Q. Huang, Enhanced in vitro anti-cancer activity of curcumin encapsulated in hydrophobically modified starch. Food Chem. 119, 669-674 (2010). https://doi.org/10.1016/J. FOODCHEM.2009.07.018

115. P. Taylor, M. Vargas, C. Pastor, A. Chiralt, Recent advances in edible coatings for fresh and minimally processed fruits. Crit. Rev. Food Sci. Nutr. 48, 496-511 (2008). https://doi. org/10.1080/10408390701537344

116. H. Yu, Y. Huang, Qingrong Huang, Synthesis and characterization of novel antimicrobial emulsifiers from $\varepsilon$-polylysine. J. Agric. Food Chem. 58, 1290-1295 (2010). https://doi. org/10.1021/jf903300m

117. M.R. Mozafari, C. Johnson, C. Demetzos, Nanoliposomes and their applications in food. J. Liposome Res. 18, 309-327 (2008). https://doi.org/10.1080/08982100802465941

118. R. Vidhyalakshmi, R. Bhakyaraj, R.S. Subhasree, Encapsulation"the future of probiotics"-a review. Adv. Biol. Res. 3, 96-103 (2009)

119. M. Karavolos, A. Holban, Nanosized drug delivery systems in gastrointestinal targeting: interactions with microbiota. 
Pharmcaeutics 9, 1-15 (2016). https://doi.org/10.3390/ph904 0062

120. K. Hu, X. Huang, Y. Gao, X. Huang, H. Xiao, D.J. McClements, Core-shell biopolymer nanoparticle delivery systems: synthesis and characterization of curcumin fortified zein-pectin nanoparticles. Food Chem. 182, 275-281 (2015). https:// doi.org/10.1016/J.FOODCHEM.2015.03.009

121. L. Zou, B. Zheng, R. Zhang, Z. Zhang, W. Liu, C. Liu, H. Xiao, D.J. McClements, Enhancing the bioaccessibility of hydrophobic bioactive agents using mixed colloidal dispersions: curcumin-loaded zein nanoparticles plus digestible lipid nanoparticles. Food Res. Int. 81, 74-82 (2016). https:// doi.org/10.1016/J.FOODRES.2015.12.035

122. J. Chen, J. Zheng, E.A. Decker, J. Mcclements, Improving nutraceutical bioavailability using mixed colloidal delivery systems: lipid nanoparticles increase tangeretin bioaccessibility and absorption from tangeretin-loaded zein nanoparticles. RSC Adv. 5, 73892-73900 (2015). https://doi.org/10.1039/ C5RA13503F

123. Y. Mao, D.J. Mcclements, Modulation of food texture using controlled heteroaggregation of lipid droplets: principles and applications. J. Appl. Polym. Sci. 130, 3833-3841 (2013). https://doi.org/10.1002/app.39631

124. C. Maier, B. Zeeb, J. Weiss, Investigations into aggregate formation with oppositely charged oil-in-water emulsions at different pH values. Colloids Surf. B 117, 368-375 (2014). https://doi.org/10.1016/J.COLSURFB.2014.03.012

125. Y. Zhu, Y. Zhang, G. Shi, J. Yang, J. Zhang, W. Li, A. Li, R. Tai, Nanodiamonds act as Trojan horse for intracellular delivery of metal ions to trigger cytotoxicity. Part. Fibre Toxicol. 12, 1-11 (2015). https://doi.org/10.1186/s12989-014-0075-Z

126. Y. Li, M. Hu, Y. Du, H. Xiao, D.J. McClements, Control of lipase digestibility of emulsified lipids by encapsulation within calcium alginate beads. Food Hydrocolloids 25, 122-130 (2011). https://doi.org/10.1016/J.FOODH YD.2010.06.003

127. N. Garti, A. Aserin, Nanoscale liquid self-assembled dispersions in foods and the delivery of functional ingredients, in: Understanding and Controlling the Microstructure of Complex Foods (Woodhead Publishing Ltd; Cambridge, UK, 2007), pp. 504-553

128. R. Solaro, F. Chiellini, A. Battisti, Targeted delivery of protein drugs by nanocarriers. Materials 3, 1928-1980 (2010). https://doi.org/10.3390/ma3031928

129. M.H. Shahavi, M. Hosseini, M. Jahanshahi, R.L. Meyer, G.N. Darzi, Evaluation of critical parameters for preparation of stable clove oil nanoemulsion. Arab. J. Chem. 12, 3225-3232 (2019). https://doi.org/10.1016/J.ARABJC.2015.08.024

130. Q. Huang, P. Given, M. Qian, Micro/nano encapsulation of active food ingredients, $1 \mathrm{st}$ edn. (American Chemical Society, Washington, DC., 2009)

131. A.L.B. Iris, $\mathrm{Ca}_{2}{ }^{+}$cross-linked alginic acid nanoparticles for solubilization of lipophilic natural colorants. J. Agric. Food Chem. 57, 7505-7512 (2009). https://doi.org/10.1021/jf900 $563 \mathrm{a}$
132. V.R. Sinha, Vinay, Anamika, J. R. Bhinge, Nanocochleates: A novel drug delivery technology. Pharmaceutical Rev. 6 (2008)

133. H. Laroui, P. Rakhya, B. Xiao, E. Viennois, D. Merlin, Nanotechnology in diagnostics and therapeutics for gastrointestinal disorders. Dig. Liver Dis. 45, 995-1002 (2013). https://doi. org/10.1016/J.DLD.2013.03.019

134. K. Rajasundari, K. Ilamurugu, Nanotechnology and its applications in medical diagnosis. J. Basic. Appl. Chem. 1, 26-32 (2011)

135. A.K. Singh, S.H. Harrison, J.S. Schoeniger, Gangliosides as receptors for biological toxins: development of sensitive fluoroimmunoassays using ganglioside-bearing liposomes. Anal. Chem. 72, 6019-6024 (2000). https://doi.org/10.1021/ ac0008461

136. L. Gu, T. Elkin, X. Jiang, H. Li, Y. Lin, L. Qu, T.J. Tzeng, R. Joseph, Y. Sun, Single-walled carbon nanotubes displaying multivalent ligands for capturing pathogens. Chem. Commun. 7, 874-876 (2005). https://doi.org/10.1039/b415015e

137. G.A. Zelada-guille, S.V. Bhosale, J. Riu, F.X. Rius, Realtime potentiometric detection of bacteria in complex samples. Anal. Chem. 82, 9254-9260 (2010)

138. S.H. Huang, Gold nanoparticle-based immunochromatographic assay for the detection of Staphylococcus aureus. Sensor Actuat. B 127, 335-340 (2007). https://doi. org/10.1016/J.SNB.2007.04.027

139. R.L. Phillips, O.R. Miranda, C. You, V.M. Rotello, Rapid and efficient identification of bacteria using gold-nanoparticlepoly (para-phenyleneethynylene) constructs. Angew. Chem. Int. Ed. 47, 2590-2594 (2008). https://doi.org/10.1002/ anie. 200703369

140. A. Llorens, E. Lloret, P.A. Picouet, R. Trbojevich, A. Fernandez, Metallic-based micro and nanocomposites in food contact materials and active food packaging. Trends Food Sci. Technol. 24, 19-29 (2012). https://doi.org/10.1016/J. TIFS.2011.10.001

141. A.I. Cano, A., C. González-martínez, Silver composite materials and food packaging. In Composites Materials for Food Packaging (Wiley, 2018)), pp. 123-151. https://doi. org/10.1002/9781119160243.ch3

142. A. Fernández, P. Picouet, E. Lloret, Cellulose-silver nanoparticle hybrid materials to control spoilage-related microflora in absorbent pads located in trays of fresh-cut melon. Int. J. Food Microbiol. 142, 222-228 (2010). https://doi. org/10.1016/J.IJFOODMICRO.2010.07.001

143. S. Valiyaveettil, Y. Teow, P.V. Asharani, M. Prakash, S. Valiyaveettil, Health impact and safety of engineered nanomaterials. Chem. Commun. 47, 7025-7038 (2011). https://doi. org/10.1039/c0cc05271j

144. K. Tiede, A.B.A. Boxall, S.P. Tear, J. Lewis, H. David et al., Detection and characterization of engineered nanoparticles in food and the environment. Food Addit. Contam. Part A. 25, 795-821 (2008). https://doi.org/10.1080/026520308020075 53

145. A.M. Schrand, M.F. Rahman, S.M. Hussain, J.J. Schlager, D.A. Smith, A.F. Syed, Metal-based nanoparticles and their toxicity assessment Amanda. Wiley Interdiscip. Rev. 
Nanomed. Nanobiotechnol. 2, 544-568 (2010). https://doi. org/10.1002/wnan.103

146. M.J. Hajipour, K.M. Fromm, A.A. Akbar Ashkarran, D. Jimenez de Aberasturi, I.R. de Larramendi et al., Antibacterial properties of nanoparticles. Trends Biotechnol. 30, 499-511 (2012). https://doi.org/10.1016/j.tibtech.2012.06.004

147. B. Mao, J. Tsai, C. Chen, S. Yan, B. Mao, J. Tsai, C. Chen, S. Yan, Y. Wang, Mechanisms of silver nanoparticleinduced toxicity and important role of autophagy. Nanotoxicol. 10, 1021-1040 (2016). https://doi.org/10.1080/17435 390.2016.1189614

148. V. Valdiglesias, C. Costa, V. Sharma, G. Kiliç, E. Pásaro, J.P. Teixeira, A. Dhawan, B. Laffon, Comparative study on effects of two different types of titanium dioxide nanoparticles on human neuronal cells. Food Chem. Toxicol. 57, 352-361 (2013). https://doi.org/10.1016/J.FCT.2013.04.010

149. M.C. Botelho, C. Costa, S. Silva, S. Costa, A. Dhawan, P.A. Oliveira, J.P. Teixeira, Effects of titanium dioxide nanoparticles in human gastric epithelial cells in vitro. Biomed. Pharmacother. 68, 59-64 (2014). https://doi.org/10.1016/J.BIOPH A.2013.08.006

150. Z. Magdolenova, A.R. Collins, A. Kumar, A. Dhawam, V. Stone, M. Dusinska, Mechanisms of genotoxicity. A review of in vitro and in vivo studies with engineered nanoparticles. Nanotoxicol 8, 233-278 (2014). https://doi. org/10.3109/17435390.2013.773464

151. A. Kumar, A. Dhawan, Genotoxic and carcinogenic potential of engineered nanoparticles: an update. Arch. Toxicol. 87, 1883-1900 (2013). https://doi.org/10.1007/s0020 4-013-1128-z

152. A.K. Shukla, P. Pragya, D.K. Chowdhuri, A modified alkaline Comet assay for in vivo detection of oxidative DNA damage in Drosophila melanogaster. Mutat. Res. Toxicol. Environ. Mutagen. 726, 222-226 (2011). https://doi.org/10.1016/J. MRGENTOX.2011.09.017

153. X. Guo, T. Chen, Progress in genotoxicity evaluation of engineered nanomaterials. Nanomater. Toxicity Risk Assess. (2015). https://doi.org/10.5772/61013

154. A.M. Knaapen, C. Albrecht, A. Becker, A. Winzer, G.R. Haenen, P.J.A. Borm, R.P.F. Schins, DNA damage in lung epithelial cells isolated from rats exposed to quartz: role of surface reactivity and neutrophilic inflammation. Carcinogenesis $\mathbf{2 3}$, 1111-1120 (2002). https://doi.org/10.1093/carcin/23.7.1111

155. A. Xu, Y. Chai, T. Nohmi, T.K. Hei, Genotoxic responses to titanium dioxide nanoparticles and fullerene in gpt delta transgenic MEF cells. Part. Fibre Toxicol. 6, 1-13 (2009). https://doi.org/10.1186/1743-8977-6-3

156. A. Kumar, A.K. Pandey, S.S. Singh, R. Shanker, A. Dhawan, Engineered $\mathrm{ZnO}$ and $\mathrm{TiO}_{2}$ nanoparticles induce oxidative stress and DNA damage leading to reduced viability of Escherichia coli. Free Rad. Biol. Med. 51, 1872-1881 (2011). https://doi.org/10.1016/J.FREERADBIOMED.2011.08.025

157. M. Wojewódzka, A. Lankoff, M. Dusińska, G. Brunborg, J. Czerwińska, T. Iwaneńko, T. Stępkowski, I. Szumiel, Treatment with silver nanoparticles delays repair of X-ray induced DNA damage in HepG2 cells. Nukleonika 56, 29-33 (2011)
158. V.A. Senapati, A. Kumar, G.S. Gupta, A.K. Pandey, A. Dhawan, $\mathrm{ZnO}$ nanoparticles induced inflammatory response and genotoxicity in human blood cells: a mechanistic approach. Food Chem. Toxicol. 85, 61-70 (2015). https:// doi.org/10.1016/J.FCT.2015.06.018

159. Q. Xia, H.-M. Hwang, P.C. Ray, H. Yu, Mechanisms of nanotoxicity: generation of reactive oxygen species. J. Food Drug. Anal. 22, 64-75 (2014). https://doi.org/10.1016/J. JFDA.2014.01.005

160. H. Bouwmeester, S. Dekkers, M.Y. Noordam, W.I. Hagens, A.S. Bulder et al., Review of health safety aspects of nanotechnologies in food production. Regul. Toxicol. Pharmacol. 53, 52-62 (2009). https://doi.org/10.1016/J.YRTPH .2008 .10 .008

161. C. Mouneyrac, P. Buffet, L. Poirier, Fate and effects of metalbased nanoparticles in two marine invertebrates, the bivalve mollusc Scrobicularia plana and the annelid polychaete Hediste diversicolor. Environ. Sci. Pollut. Res. 21, 78997912 (2014). https://doi.org/10.1007/s11356-014-2745-7

162. L. Xu, X. Li, T. Takemura, N. Hanagata, G. Wu, L.L. Chou, Genotoxicity and molecular response of silver nanoparticle (NP) -based hydrogel. J. Nanobiotechnol. 10, 1-11 (2012). https://doi.org/10.1186/1477-3155-10-16

163. K. Kansara, P. Patel, D. Shah, R.K. Shukla, S. Singh, A. Kumar, A. Dhawan, $\mathrm{TiO}_{2}$ nanoparticles induce DNA double strand breaks and cell cycle arrest in human alveolar cells. Environ. Mol. Mutagen. 56, 204-217 (2015). https://doi. org/10.1002/em.21925

164. J.Y. Kwon, S.Y. Lee, P. Koedrith, J.Y. Lee, K.-M. Kim et al., Lack of genotoxic potential of $\mathrm{ZnO}$ nanoparticles in in vitro and in vivo tests. Mutat. Res. Toxicol. Environ. Mutagen. 761, 1-9 (2014). https://doi.org/10.1016/J.MRGEN TOX.2014.01.005

165. Ü. Kumbıçak, T. Çavaş, N. Çinkılıç, Z. Kumbıçak, Ö. Vatan, D. Y1lmaz, Evaluation of in vitro cytotoxicity and genotoxicity of copper-zinc alloy nanoparticles in human lung epithelial cells. Food Chem. Toxicol. 73, 105-112 (2014). https:// doi.org/10.1016/J.FCT.2014.07.040

166. C. Badgley, J. Moghtader, E. Quintero, E. Zakem, M.J. Chappell, Organic agriculture and the global food supply. Renew. Agric. Food Syst. 22, 86-108 (2007). https://doi.org/10.1017/ S1742170507001640

167. D.M. Bowman, G.A. Hodge, Nanotechnology: mapping the wild regulatory frontier. Futures 38, 1060-1073 (2006). https ://doi.org/10.1016/J.FUTURES.2006.02.017

168. F. Cubadda, F. Aureli, A. Raggi, M. Cristina, B. Toscan, A. Mantovani, Nanotechnologies and nanomaterials in the food sector and their safety assessment. Rapp. ISTISAN 13, 48 (2016)

169. S. Tinkle, S.E. Mcneil, M. Stefan, R. Bawa, G. Borchard, Nanomedicines: addressing the scientific and regulatory gap. Ann. New York Acad. Sci. 1313, 35-56 (2014). https://doi. org/10.1111/nyas.12403

170. N.O. Brien, E. Cummins, Ranking initial environmental and human health risk resulting from environmentally relevant 
nanomaterials. J. Environ. Sci. Health A 45, 992-1007 (2010). https://doi.org/10.1080/10934521003772410

171. C. Buzea, Nanomaterials and nanoparticles: sources and toxicity. Biointerphases 2, 17-71 (2007). https://doi. org/10.1116/1.2815690

172. F. González-nilo, T. Pérez-acle, S. Guínez-, Nanoinformatics: an emerging area of information technology at the intersection of bioinformatics, computational chemistry and nanobiotechnology. Biol. Res. 44, 43-51 (2011). https://doi. org/10.4067/S0716-97602011000100006

173. Center for Food Safety (2017). (www.centerforfoodsafety.org) Retrieved from http://salsa3.salsalabs.com/o/1881/p/salsa /web/common/public/content?content_item_KEY=14112 $\% 20 \#$ showJoin

174. N. Pradhan, S. Singh, N. Ojha, A. Shrivastava, A. Barla, V. Rai, S. Bose, Facets of Nanotechnology as seen in food processing, packaging, and preservation industry. Biomed. Res. Int. 2015, 1-17 (2015). https://doi.org/10.1155/2015/365672

175. A. Gramza-Michałowska, D. Kmiecik, J. Kobus-Cisowska, A. Żywica, K. Dziedzic, A. Brzozowska, Phytonutrients in oat (Avena sativa L.) Drink : Effect of plant extract on antiradical capacity, nutritional value and sensory characteristics. Pol. J. Food Nutr. Sci. 68, 63-71 (2018). https://doi.org/10.1515/ pjfns-2017-0009

176. K. Pathakoti, M. Manubolu, H.-M. Hwang, Nanostructures: current uses and future applications in food science. J. Food Drug Anal. 25, 245-253 (2017). https://doi.org/10.1016/J. JFDA.2017.02.004

177. H.A. Lee, Effect of nanometric Lactobacillus plantarum in kimchi on dextran sulfate sodium-induced colitis in mice. J. Med. Food 18, 1073-1080 (2015). https://doi.org/10.1089/ jmf.2015.3509

178. L. Rashidi, K. Khosravi-Darani, The applications of nanotechnology in food industry. Crit. Rev. Food Sci. Nutr. 51, 723-730 (2011). https://doi.org/10.1080/104083910037854 17

179. N. Walia, N. Dasgupta, S. Ranjan, C. Ramalingam, M. Gandhi, Food-rade nanoencapsulation of vitamins. Environ. Chem. Lett. 17, 991-1002 (2019). https://doi.org/10.1007/ s10311-018-00855-9

180. A.Y. Pawar, K.R. Jadhav, N.B. Sonkamble, M.R. Kale, Nanocochleate: a novel drug delivery system. Asian J. Pharm 10, 234-242 (2016)

181. B. Chatterjee, Synthetic Lycopene: the future but unaware fact. Int. J. Clin. Biomed. Res. 2, 14-18 (2016)

182. M. Rossi, D. Passeri, A. Sinibaldi, M. Angjellari, E. Tamburri, A. Sorbo, E. Carata, L. Dini, Nanotechnology for food packaging and food quality assessment. Adv. Food Nutr. Res. 82, 149-204 (2017). https://doi.org/10.1016/ BS.AFNR.2017.01.002

183. E.H. Chowdhury, T. Akaike, Fibronectin-coated nano-precipitates of calcium-magnesium phosphate for integrin-targeted gene delivery. J. Controlled Release 116, 68-69 (2006). https ://doi.org/10.1016/j.jconrel.2006.09.053
184. K. Jennifer, The Nanotechnology-Biology Interface: Exploring Models for Oversight, Workshop Report (Center for Science, Technology, and Public Policy, 2005)

185. N. Jones, B. Ray, K.T. Ranjit, A.C. Manna, Antibacterial activity of $\mathrm{ZnO}$ nanoparticle suspensions on a broad spectrum of microorganisms. FEMS Microbiol. Lett. 279, 71-76 (2008). https://doi.org/10.1111/j.1574-6968.2007.01012.x

186. R. Zhao, P. Torley, P.J. Halley, Emerging biodegradable materials: starch- and protein-based bio-nanocomposites. J. Mater. Sci. 43, 3058-3071 (2008). https://doi.org/10.1007/ s10853-007-2434-8

187. E. Acosta, Bioavailability of nanoparticles in nutrient and nutraceutical delivery. Curr. Opin. Colloid Interface Sci. 14, 3-15 (2009). https://doi.org/10.1016/J.COCIS.2008.01.002

188. K. Arshak, C. Adley, E. Moore, C. Cunniffe, M. Campion, J. Harris, Characterisation of polymer nanocomposite sensors for quantification of bacterial cultures. Sensor Actuat. B 126, 226-231 (2007). https://doi.org/10.1016/J.SNB.2006.12.006

189. Y. Xing, Q. Xu, X. Li, C. Chen, L. Ma, S. Li, Z. Che, H. Lin, Chitosan-based coating with antimicrobial agents: preparation, property, mechanism, and application effectiveness on fruits and vegetables. Int. J. Polym. Sci. 5, 1-24 (2016). https ://doi.org/10.1155/2016/4851730

190. C. Ozdemir, F. Yeni, D. Odaci, S. Timur, Electrochemical glucose biosensing by pyranose oxidase immobilized in gold nanoparticle-polyaniline/ $\mathrm{AgCl} /$ gelatin nanocomposite matrix. Food Chem. 119, 380-385 (2010). https://doi.org/10.1016/J. FOODCHEM.2009.05.087

191. R. Antiochia, I. Lavagnini, F. Magno, Amperometric mediated carbon nanotube paste biosensor for fructose determination paste biosensor for fructose. Anal. Lett. 37, 1657-1669 (2007). https://doi.org/10.1081/AL-120037594

192. S. Viswanathan, H. Radecka, J. Radecki, Electrochemical biosensor for pesticides based on acetylcholinesterase immobilized on polyaniline deposited on vertically assembled carbon nanotubes wrapped with ssDNA. Biosens. Bioelectron. 24, 2772-2777 (2009). https://doi.org/10.1016/J. BIOS.2009.01.044

193. M. Tominaga, S. Nomura, I. Taniguchi, d-Fructose detection based on the direct heterogeneous electron transfer reaction of fructose dehydrogenase adsorbed onto multi-walled carbon nanotubes synthesized on platinum electrode. Biosens. Bioelectron. 24, 1184-1188 (2009). https://doi.org/10.1016/J. BIOS.2008.07.002

194. X. Li, Y. Zhou, Z. Zheng, X. Yue, Z. Dai, S. Liu, Z. Tang, Glucose biosensor based on nanocomposite films of CdTe quantum dots and glucose oxidase. Langmuir 25, 6580-6586 (2009). https://doi.org/10.1021/la900066z

195. H. Zhang, J. Wang, S. Ye, Predictions of acidity, soluble solids and firmness of pear using electronic nose technique. J. Food Eng. 86, 370-378 (2008). https://doi.org/10.1016/J. JFOODENG.2007.08.026

196. M. Wang, Z. Li, Nano-composite $\mathrm{ZrO} 2 / \mathrm{Au}$ film electrode for voltammetric detection of parathion. Sensor Actuat. B 133, 607-612 (2008). https://doi.org/10.1016/J.SNB.2008.03.023 
197. K. El-boubbou, C. Gruden, X. Huang, Magnetic glyco-nanoparticles: a unique tool for rapid pathogen detection, decontamination, and strain differentiation. J. Am. Chem. Soc. 129, 13392-13393 (2007). https://doi.org/10.1021/ja076086e

198. Y. Liju Yang, Li, Quantum dots as fluorescent labels for quantitative detection of Salmonella typhimurium in chicken carcass wash water. J. Food Prot. 68, 1241-1245 (2005)

199. R.S. Norman, J.W. Stone, A. Gole, C.J. Murphy, T.L. Saboattwood, Targeted photothermal lysis of the pathogenic bacteria Pseudomonas aeruginosa with Gold Nanorods. Nano Lett. 8, 302-306 (2008). https://doi.org/10.1021/n10727056

200. A.S. Nanoshells, S.A. Kalele, A.A. Kundu, S.W. Gosavi, D.N. Deobagkar, D.D. Deobagkar, S.K. Kulkarni, Rapid detection of Escherichia coli by using antibody-conjugated silver nanoshells. Small 2, 335-338 (2006). https://doi.org/10.1002/ smll.200500286

201. B.J. Yakes, R.J. Lipert, J.P. Bannantine, M.D. Porter, Detection of Mycobacterium avium subsp. paratuberculosis by a sonicate immunoassay based on surface-enhanced raman scattering. Clin. Vaccine Immunol. 15, 227-234 (2008). https ://doi.org/10.1128/cvi.00334-07

202. A.C. Vinayaka, S. Basheer, M.S. Thakur, Bioconjugation of CdTe quantum dot for the detection of 2,4-dichlorophenoxyacetic acid by competitive fluoroimmunoassay based biosensor. Biosens. Bioelectron. 24, 1615-1620 (2009). https://doi.org/10.1016/j.bios.2008.08.042

203. X. Ji, J. Zheng, J. Xu, V.K. Rastogi, T. Cheng, J.J. Defrank, R.M. Leblanc, (CdSe) ZnS quantum dots and organophosphorus hydrolase bioconjugate as biosensors for detection of paraoxon. J. Phys. Chem. B. 109, 3793-3799 (2005). https://doi.org/10.1021/jp044928f

204. A.L. Simonian, T.A. Good, S.S. Wang, J.R. Wild, Nanoparticle-based optical biosensors for the direct detection of organophosphate chemical warfare agents and pesticides. Anal. Chim. Acta 534, 69-77 (2005). https://doi. org/10.1016/j.aca.2004.06.056

205. H. Wei, E. Wang, X.Y.N. Nanotechnol, $\mathrm{Fe}_{3} \mathrm{O}_{4}$ Magnetic nanoparticles as peroxidase mimetics and their applications in $\mathrm{H}_{2} \mathrm{O}_{2}$ and glucose detection. Anal. Chem. 80, 2250-2254 (2008)

206. M.G. Sandros, V. Shete, D.E. Benson, Selective, reversible, reagentless maltose biosensing with core-shell semiconducting nanoparticles. Analyst 131, 229-235 (2006). https ://doi.org/10.1039/b511591d

207. G. Thangavel, S. Thiruvengadam, Nanotechnology in food industry—a review. Int. J. Chem. Tech. Res. 6, 4096-4101 (2014)

208. R.B. Reed, J.J. Faust, Y. Yang, K. Doudrick, D.G. Capco, K. Hristovski, P. Westerho, Characterization of nanomaterials in metal colloid-containing dietary supplement drinks and assessment of their potential interactions after ingestion. ACS Sustain. Chem. Eng. 2, 1616-1624 (2014). https ://doi.org/10.1021/sc500108m

209. A.K. Sundramoorthy, S. Gunasekaran, Applications of graphene in quality assurance and safety of food. TrAC-Trends
Anal. Chem. 60, 36-53 (2014). https://doi.org/10.1016/J. TRAC.2014.04.015

210. H. Yu, C. Yan, J. Yao, Fully biodegradable food packaging materials based on functionalized cellulose nanocrystals/ poly(3-hydroxybutyrate-co-3-hydroxyvalerate) nanocomposites. RSC Adv. 4, 59792-59802 (2014). https://doi. org/10.1039/C4RA12691B

211. R. Augustine, A.R. Abraham, N. Kalarikkal, S. Thomas, Novel Approaches of Nanotechnology in Food (Academic Press, Oxford, 2016)

212. T. Lorne, M. Jiménez-Ruiz, S. Rols, J.-M. Escudier, J. Rubio-Zuazo et al., Competition between covalent and noncovalent grafting of fluorescein isothiocyanate on doublewalled carbon nanotubes: a quantitative approach. Carbon 123, 735-743 (2017). https://doi.org/10.1016/J.CARBO N.2017.07.070

213. C.J. Barrow, C. Nolan, B.J. Holub, Bioequivalence of encapsulated and microencapsulated fish-oil supplementation. J. Funct. Foods 1, 38-43 (2009). https://doi.org/10.1016/J. JFF.2008.09.006

214. E. Bouyer, G. Mekhloufi, V. Rosilio, J.-L. Grossiord, F. Agnely, Proteins, polysaccharides, and their complexes used as stabilizers for emulsions: alternatives to synthetic surfactants in the pharmaceutical field. Int. J. Pharm. 436, 359378 (2012). https://doi.org/10.1016/J.IJPHARM.2012.06.052

215. S. Emami, S. Azadmard-damirchi, S.H. Peighambardoust, H. Valizadeh, J. Hesari, Liposomes as carrier vehicles for functional compounds in food sector. J. Exp. Nanosci. 11, 737-759 (2016). https://doi.org/10.1080/17458 080.2016 .1148273

216. T. Ghorbanzade, S.M. Jafari, S. Akhavan, R. Hadavi, Nanoencapsulation of fish oil in nano-liposomes and its application in fortification of yogurt. Food Chem. 216, 146-152 (2017). https://doi.org/10.1016/J.FOODCHEM.2016.08.022

217. I. Barwal, A. Sood, M. Sharma, B. Singh, S.C. Yadav, Development of stevioside Pluronic-F-68 copolymer based PLA-nanoparticles as an antidiabetic nanomedicine. Colloids Surface B 101, 510-516 (2013). https://doi. org/10.1016/J.COLSURFB.2012.07.005

218. H. Singh, Nanotechnology applications in functional foods: opportunities and challenges. Prev. Nutr. Food Sci. 21, 1-8 (2016). https://doi.org/10.3746/pnf.2016.21.1.1

219. T. Mehmood, Optimization of the canola oil based vitamin E nanoemulsions stabilized by food grade mixed surfactants using response surface methodology. Food Chem. 183, 1-7 (2015). https://doi.org/10.1016/J.FOODCHEM.2015.03.021

220. I. Cho, S. Ku, Current technical approaches for the early detection of foodborne pathogens: challenges and opportunities. Int. J. Mole. Sci. 18, 2078 (2017). https://doi. org/10.3390/ijms 18102078

221. B. Dalzon, C. Lebas, G. Jimenez, A. Gutjahr, C. Terrat, J. Exposito, B. Verrier, C. Lethias, Poly (lactic acid) nanoparticles targeting $\alpha 5 \beta 1$ integrin as vaccine delivery vehicle: A prospective study. PLoS ONE 11, 1-18 (2016). https:// doi.org/10.1371/journal.pone.0167663 
222. M.A. Mohammed, J.T.M. Syeda, K.M. Wasan, E.K. Wasan, An overview of chitosan nanoparticles and its application in non-parenteral drug delivery. Pharmcaeutics 9, 1-26 (2017). https://doi.org/10.3390/pharmaceutics9040053

223. B. Kuswandi, Environmental friendly food nano-packaging. Environ. Chem. Lett. 15(2), 205-221 (2017). https://doi. org/10.1007/s10311-017-0613-7

224. B. Malhotra, A.N.U. Keshwani, H. Kharkwal, Natural polymer based cling films for food packaging. Int. J. Pharm. Pharm. Sci. 7, 10-18 (2015)

225. S. Malaysiana, K. Mengenai, T. Hijau, D. Selenium, K. Penguatan et al., A Review on selenium-enriched green tea: fortification methods, biological activities and application prospect. Sains Malays. 43, 1685-1692 (2014)

226. M.H. Fulekar, Nanotechnology: Importance and Applications (Ik Publishers International Pvt Ltd, New Delhi, 2010)

227. H. Ardalani, A. Avan, M. Ghayour-mobarhan, Podophyllotoxin: a novel potential natural anticancer agent. Avicenna J. Phytomed. 7, 285-294 (2017)

228. B. Hu, X. Liu, C. Zhang, X. Zeng, Food macromolecule based nanodelivery systems for enhancing the bioavailability of polyphenols. J. Food Drug Anal. 25, 3-15 (2017). https://doi.org/10.1016/J.JFDA.2016.11.004

229. X. He, H.-M. Hwang, Nanotechnology in food science: functionality, applicability, and safety assessment. J. Food Drug Anal. 24, 671-681 (2016). https://doi.org/10.1016/J. JFDA.2016.06.001

230. C.J. Wijaya, S.N. Saputra, F.E. Soetaredjo, J.N. Putro, C.X. Lin, A. Kurniawan, Y.-H. Ju, S. Ismadji, Cellulose nanocrystals from passion fruit peels waste as antibiotic drug carrier. Carbohydr. Polym. 175, 370-376 (2017). https ://doi.org/10.1016/J.CARBPOL.2017.08.004

231. L. Wang, C. Hu, The antimicrobial activity of nanoparticles: present situation and prospects for the future. Int. J. Nanomed. 12, 1227-1249 (2017)

232. V. Rastogi, P. Yadav, S.S. Bhattacharya, A.K. Mishra, N. Verma, A. Verma, J.K. Pandit, Carbon nanotubes : an emerging drug carrier for targeting cancer cells. J. Drug Deliv. 10, 1-24 (2014). https://doi. org/10.1016/10.1155/2014/670815

233. H. Jiang, D. Jiang, J. Shao, X. Sun, J. Wang, High-throughput living cell-based optical biosensor for detection of bacterial lipopolysaccharide (LPS) using a red fluorescent protein reporter system. Sci. Rep. 6, 1-12 (2016). https:// doi.org/10.1038/srep36987

234. N.K. Jain, V. Mishra, N.K. Mehra, N.K. Jain, V. Mishra, N.K. Mehra, Targeted drug delivery to macrophages. Expert Opin. Drug Deliv. 10, 353-367 (2013). https://doi. org/10.1517/17425247.2013.751370

235. T.K. Głab, J. Boratynski, Potential of casein as a carrier for biologically active. Top. Curr. Chem. 375, 1-20 (2017). https://doi.org/10.1007/s41061-017-0158-Z

236. K.P. Chandrika, A. Singh, M.K. Tumma, P. Yadav, Nanotechnology prospects and constraints in agriculture, in Environmental chemistry for a sustainable world, vol. 14, ed. by N. Dasgupta, S. Ranjan, E. Lichtfouse (Springer, New York, 2018)

237. O. Betzer, R. Meir, T. Dreifuss, K. Shamalov, M. Motiei, A. Shwartz, K. Baranes, C.J. Cohen, N. Shraga-heled, R. Ofir, In-vitro optimization of nanoparticle-cell labeling protocols for In-vivo Cell tracking applications. Sci. Rep. 5, 15400 (2015). https://doi.org/10.1038/srep15400

238. H.D. Silva, M.Â. Cerqueira, A.A. Vicente, Nanoemulsions for food applications: development and characterization. Food Bioprocess Technol. 5, 854-867 (2012). https://doi. org/10.1007/s11947-011-0683-7

239. K.M. Nelson, J.L. Dahlin, J. Bisson, J. Graham, G.F. Pauli, M.A. Walters, The essential medicinal chemistry of curcumin. J. Med. Chem. 60, 1620-1637 (2017). https://doi. org/10.1021/acs.jmedchem.6b00975

240. D. Kim, S.J. Kwon, X. Wu, J. Sauve, I. Lee, J. Nam, J. Kim, J.S. Dordick, Selective killing of pathogenic bacteria by antimicrobial silver nanoparticle-cell wall binding domain conjugates. ACS Appl. Mater. Interfaces. 10, 13317-13324 (2018). https://doi.org/10.1021/acsami.8b00181

241. X. Su, P. Liu, H. Wu, N. Gu, Enhancement of radiosensitization by metal-based nanoparticles in cancer radiation therapy. Cancer Biol. Med. 11, 86-91 (2014). https://doi. org/10.7497/j.issn.2095-3941.2014.02.003

242. L.A. Dykman, N.G. Khlebtsov, Gold nanoparticles in biology and medicine: recent advances and prospects. ACTA Nat. 3, 34-55 (2011). https://doi.org/10.111 $1 / \mathrm{j} .1600-0854.2010 .01156 . \mathrm{x}$

243. X. Gao, S.R. Dave, Advances in Experimental Medicine and Biology (Springer, New York, 2007)

244. Z. Bakhtiary, A.A. Saei, M.J. Hajipour, M. Raoufi, O. Vermesh, M. Mahmoudi, Targeted superparamagnetic iron oxide nanoparticles for early detection of cancer: possibilities and challenges. Nanomed. Nanotechnol. Biol. Med. 12, 287-307 (2016). https://doi.org/10.1016/J. NANO.2015.10.019

245. U. Kedar, P. Phutane, S. Shidhaye, V. Kadam, Advances in polymeric micelles for drug delivery and tumor targeting. Nanomed. Nanotechnol. Biol. Med. 6, 714-729 (2010). https://doi.org/10.1016/J.NANO.2010.05.005

246. D. Goswami, S.K. Medda, G. De, Superhydrophobic films on glass surface derived from trimethylsilanized silica gel nanoparticles. ACS Appl. Mater. Interfaces. 3, 3440-3447 (2011). https://doi.org/10.1021/am200666m

247. F. Danhier, O. Feron, V. Préat, To exploit the tumor microenvironment: passive and active tumor targeting of nanocarriers for anti-cancer drug delivery. J. Controlled Release 148, 135-146 (2010). https://doi.org/10.1016/J.JCONR EL.2010.08.027

248. M. Hirenkumar, S. Steven, Poly lactic-co-glycolic acid (PLGA) as biodegradable controlled drug delivery carrier. Polymers 3, 1-19 (2012). https://doi.org/10.3390/polym 3031377.Poly

249. H. Sun, Y. Sakka, H. Sun, Y. Sakka, Luminescent metal nanoclusters: controlled synthesis and functional applications luminescent metal nanoclusters: controlled 
synthesis and functional applications. Sci. Technol. Adv. Mater. 15, 014205 (2014). https://doi.org/10.1088/14686996/15/1/014205

250. C. Bharti, U. Nagaich, A.K. Pal, N. Gulati, Mesoporous silica nanoparticles in target drug delivery system: a review. Int. J. Pharmac. Investig. 5, 124-133 (2015). https://doi. org/10.4103/2230-973X.160844

251. F.M. Mustafa, H.A. Hodali, Use of mesoporous silicate nanoparticles as drug carrier for mefenamic acid. Marer. Sci. Eng. 92, 1-6 (2015). https://doi.org/10.1088/1757899X/92/1/012018

252. A.D. Furasova, A.F. Fakhardo, V.A. Milichko, E. Tervoort, M. Niederberger, V.V. Vinogradov, Synthesis of a rareearth doped hafnia hydrosol: towards injectable luminescent nanocolloids. Colloid Surface B 154, 21-26 (2017). https://doi.org/10.1016/J.COLSURFB.2017.02.029

253. R. Bakry, M. Najam-ul-haq, C.W. Huck, Medicinal applications of fullerenes. Int. J. Nanomed. 2, 639-649 (2007). https://doi.org/10.2147/nano.2007.2.1.117
254. G.C. Pradhan, S. Dash, S.K. Swain, Barrier properties of nano silicon carbide designed chitosan nanocomposites. Carbohydr. Polym. 134, 60-65 (2015). https://doi. org/10.1016/J.CARBPOL.2015.06.081

255. S.E. McNeil, Nanotechnology for the biologist. J. Leukoc. Biol. 78, 585-594 (2005). https://doi.org/10.1189/jlb.02050 74

256. I.K. Herrmann, How nanotechnology-enabled concepts could contribute to the prevention, diagnosis and therapy of bacterial infections. Crit. Care 19, 239 (2015). https:// doi.org/10.1186/s13054-015-0957-y

257. L. Salvia-trujillo, O. Martín-belloso, D.J. Mcclements, Excipient nanoemulsions for improving oral bioavailability of bioactives. Nanomaterials 6, 1-16 (2016). https://doi. org/10.3390/nano6010017 